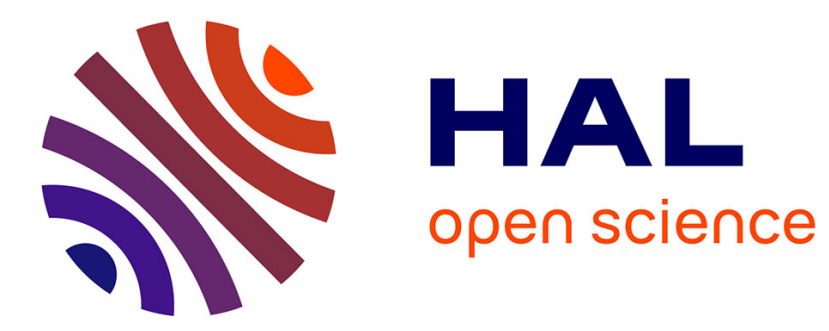

\title{
Strain rate effects on localized necking in substrate-supported metal layers
}

Mohamed Ben Bettaieb, Farid Abed-Meraim

\section{To cite this version:}

Mohamed Ben Bettaieb, Farid Abed-Meraim. Strain rate effects on localized necking in substratesupported metal layers. International Journal of Advanced Manufacturing Technology, 2017, 92 (9-12), pp.3461-3480. 10.1007/s00170-017-0344-8 . hal-01795314

\section{HAL Id: hal-01795314 https://hal.science/hal-01795314}

Submitted on 18 May 2018

HAL is a multi-disciplinary open access archive for the deposit and dissemination of scientific research documents, whether they are published or not. The documents may come from teaching and research institutions in France or abroad, or from public or private research centers.
L'archive ouverte pluridisciplinaire HAL, est destinée au dépôt et à la diffusion de documents scientifiques de niveau recherche, publiés ou non, émanant des établissements d'enseignement et de recherche français ou étrangers, des laboratoires publics ou privés. 


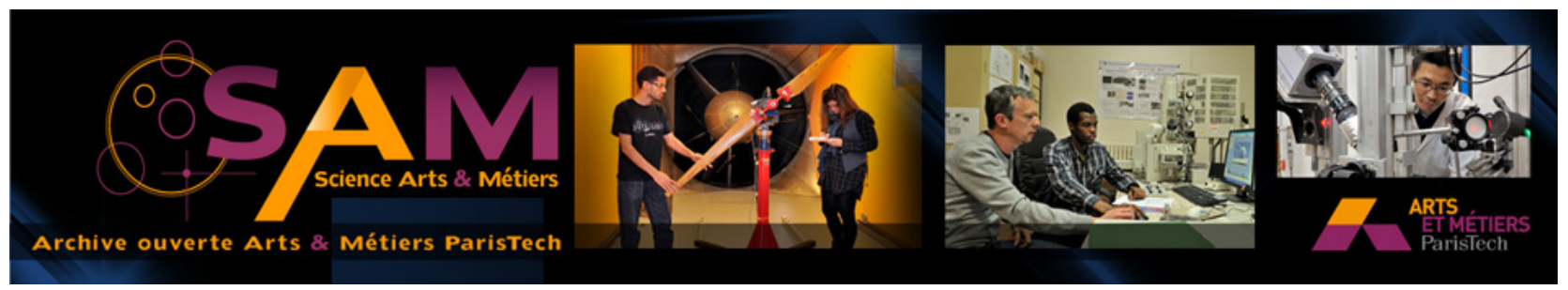

Science Arts \& Métiers (SAM)

is an open access repository that collects the work of Arts et Métiers ParisTech researchers and makes it freely available over the web where possible.

This is an author-deposited version published in: http://sam.ensam.eu Handle ID: .http://hdl.handle.net/null

\section{To cite this version :}

Mohamed BEN BETTAIEB, Farid ABED-MERAIM - Strain rate effects on localized necking in substrate-supported metal layers - The International Journal of Advanced Manufacturing Technology - Vol. 92, n॰9-12, p.3461-3480 - 2017 


\title{
Strain rate effects on localized necking in substrate-supported metal layers
}

\author{
Mohamed Ben Bettaieb ${ }^{1,2}$ - Farid Abed-Meraim ${ }^{1,2}$
}

\begin{abstract}
Due to their good mechanical and technological performances, thin substrate-supported metal layers are increasingly used as functional components in flexible electronic devices. Consequently, the prediction of necking, and the associated limit strains, for such components is of major academic and industrial importance. The current contribution aims to numerically investigate the respective and combined effects of strain rate sensitivity of the metal layer and the addition of an elastomer layer on localized necking in substrate-supported metal layers. To this end, strain ratedependent forms for the flow theory of plasticity and the deformation theory counterpart are used to describe the mechanical behavior of the metal layer. As to the substrate layer, it is made of elastomer material whose mechanical response is described by a neo-Hookean hyperelastic model. The two layers are assumed to be perfectly adhered. Necking limit strains are predicted by the Marciniak-Kuczynski (M-K) imperfection approach. Various numerical results, corresponding to freestanding metal layers as well as substrate-supported metal layers, are presented and extensively discussed in this paper. The significant effect of strain rate sensitivity on the retardation of localized necking is first emphasized. Then, the combined and positive influence of strain rate sensitivity of the metal layer and characteristics of the elastomer layer (thickness and stiffness) on the enhancement of the ductility of the whole bilayer is analyzed and discussed.
\end{abstract}

Keywords Localized necking - Substrate-supported metal layer - Strain rate effect $\cdot$ Deformation theory - Flow theory . Marciniak-Kuczynski analysis

\section{Introduction}

Sheet metal forming processes often suffer from the occurrence of localized necking due to the low ductility of the used materials. This type of plastic instability represents the ultimate deformation that a stretched sheet metal can undergo, since localized necking is often precursor to material failure. To determine the limit strains for sheet metals, the concept of forming limit diagram (FLD) was initially introduced by Keeler and Backofen [1] and Goodwin [2]. In the literature, these diagrams are determined either experimentally or using theoretical alternatives. Due to the complexity and the high cost of experimental tests, the theoretical approaches (including analytical and numerical methods) are preferred in the literature for the formability assessment of thin metallic sheets. Accordingly, the latter type of approaches is followed in the current paper. Note that in an industrial context, designing metallic parts and components with improved formability properties represents an ambitious scientific challenge. To achieve this goal, at least two strategies may be followed:

- The first one consists in using freestanding metal sheets characterized by improved mechanical properties that allow reaching a large amount of straining without occurrence of localized necking. Among these properties, strain hardening and strain rate sensitivity are of key importance. Indeed, formability increases with the strain hardening exponent, as initially demonstrated by Hill [3], who developed a localized necking approach and applied it to the prediction of limit strains for rigid-plastic materials 
following the flow theory of plasticity. The same trend, in terms of sensitivity of formability to strain hardening, was confirmed for more general constitutive frameworks, as demonstrated for instance in [4-6]. In the current work, attention is focused on the effect of strain rate sensitivity on the formability limit of both freestanding and substratesupported metal layers. This effect has been emphasized earlier by Ghosh [7] on the basis of experimental investigations carried out on various metallic materials (steel, aluminum, brass...). Concurrently, Hutchinson and Neale [8] analyzed numerically the influence of strain rate sensitivity on necking for a circular bar under uniaxial tension state. They demonstrated that a relatively small amount of strain rate dependence leads to a substantial increase in the magnitude of limit strains. The latter study has been extended by the same authors [9] to the full range of strain paths (ranging from uniaxial tension to equibiaxial expansion). In that work, an improved version of the initial imperfection approach, initially introduced by Marciniak and Kuczynski [10], has been developed and used to predict the onset of localized necking. The results obtained in [9] confirm the conclusions drawn earlier in [8]. Later, Neale and Chater [11] enlarged the study of Hutchinson and Neale [9] by taking into account the combined effects of material strain rate sensitivity and plastic anisotropy on the limit strain prediction of thin metal sheets with transversely isotropic properties. It is worth noting that, in the previous theoretical investigations, the initial imperfection approach has been exclusively used to predict strain localization in strain ratesensitive materials. More recently, other localization criteria have been adopted to assess the effect of strain rate sensitivity on strain localization, such as the perturbation approach [12]. In the present paper, the initial imperfection approach is again employed to analyze the beneficial effect of strain rate sensitivity on the retardation of strain localization in thin sheet metals. In this study, finite strain versions for both the rigid-viscoplastic flow theory and the deformation theory of plasticity are used to describe the mechanical behavior of sheet metals. For the sake of simplicity, elasticity, anisotropy, and kinematic hardening are not considered in this modeling. To validate the developed theoretical and numerical tools, the obtained numerical predictions are compared with the results reported in some pioneering works from the literature (see $[9,11])$. From these comparisons, it is clearly observed that both results match very well, thus providing theoretical and numerical validations for the developed tools.

- The second strategy to enhance formability is of technological nature and consists in perfectly bonding a metal layer to an elastomer substrate. Indeed, this solution has proven to significantly improve the stretchability of industrial devices [13-17]. Consequently, it has been widely used in several industrial applications. In this field, one can quote Cordill et al. [18] who bonded chromium (Cr) films to polyimide (PI) substrates. Cotton et al. [19] used this technological solution to develop new stretchable and multifunctional capacitive sensors made of gold thin films embedded in silicone rubber. The mechanical compliance of the gold films and silicone membranes allow the device to be bent, folded, or stretched without damage, making it a suitable candidate for electronic skin applications. Lacour et al. [20] adopted the same technology in order to develop a new generation of interconnects for elastic electronic surfaces. These interconnects are made of stripes of thin gold film patterned on elastomeric membranes. Thanks to this composition, the obtained interconnects display very good stretchability. Several other industrial fields are concerned with the application of this technological solution, such as curved imaging surfaces [21], sensors skins [22], and electronic textiles [23, 24]. Note that the representation of formability limits for substratesupported metal layers, in the form of FLDs, has been first attempted in [25], by using the bifurcation approach [26]. In their investigation, Jia and $\mathrm{Li} \mathrm{[25]} \mathrm{used} \mathrm{a} \mathrm{finite} \mathrm{strain}$ version of the rate-independent deformation theory of plasticity to describe the mechanical response of the metal layer and a neo-Hookean model for the elastomer layer. They demonstrated that the addition of elastomer substrate has an effect of increasing the predicted limit strains. For comparison purposes, the investigations of Jia and $\mathrm{Li}$ [25] have been extended in [6] by considering two additional frameworks: (i) the flow theory of plasticity, as an alternative description for the mechanical behavior of the metal layer and (ii) the initial imperfection approach, as an additional approach to localized necking. The beneficial effect of the elastomer substrate on the formability of the bilayer, initially shown in [25], has been confirmed in [6] for both constitutive theories. Moreover, it has been demonstrated in [6] that the FLDs determined by the initial imperfection approach tend towards those predicted by the bifurcation analysis in the limit of a vanishing size for the initial imperfection. This result has been shown to be valid for both freestanding metal layers and substrate-supported metal layers and also for both constitutive frameworks (flow theory and deformation theory of plasticity). In the current paper, the investigations carried out in [6] are enlarged by extending the analysis to a more general constitutive framework, which accounts for strain rate effects, in order to investigate the influence of the latter on formability. It is worth noting that, because the mechanical behavior of the metal layer is taken to be strain rate sensitive, the use of the bifurcation theory for strain localization prediction is precluded. Therefore, only the initial imperfection approach is used in this paper in order to analyze the impact of strain rate sensitivity on the 
formability limits of both freestanding metal layers and metal/elastomer bilayers. In this sense, the current contribution may also be viewed as an extension of the work carried out in [9], which was restricted to the formability prediction of freestanding metal layers. As will be shown in what follows, the main results of the current work are that both the strain rate dependency of the metal layer, on the one hand, and the addition of an elastomer layer, on the other hand, have beneficial effects on formability, as they both allow substantial retardation in the occurrence of localized necking.

The remainder of the paper is organized as follows:

- Section 2 is devoted to the description of the constitutive frameworks used to model the behavior of the metal and elastomer layers.

- In Section 3, the equations governing the initial imperfection approach are provided for the prediction of localized necking.

- Section 4 details the numerical algorithms developed for the FLD prediction based on the initial imperfection approach.

- Various numerical results and predictions are presented in Section 5, where the effects on localized necking of both the strain rate sensitivity and the addition of an elastomer layer are discussed in details.

Notations, conventions, and abbreviations The derivations presented in this paper are carried out using classic conventions. Note that the assorted notations can be combined. Additional notations will be clarified as needed, following related equations.

\footnotetext{
Vectorial and tensorial fields are designated by bold letters and symbols

Scalar variables and parameters are represented by thin letters and symbols

Einstein's convention of summation over repeated indices is adopted. The range of the free (resp. dummy) index is given before (resp. after) the corresponding equation

- time derivative of $\bullet$

${ }^{\mathrm{T}}$ transpose of tensor $\bullet$

$\longrightarrow \otimes \longrightarrow$ tensor product of two vectors $\left(=\bullet_{i}{ }^{\circ}\right)$

I value of quantity $\cdot$ at the initial time

- value of quantity $\bullet$ at time $t$ (for convenience, the dependence on time is most often omitted when the variable is expressed in the current instant)

$\bullet(*)$ quantity $\bullet$ associated with behavior in layer *

- ${ }^{\mathrm{B}}$ quantity $\bullet$ associated with behavior in the band

-S quantity $\cdot$ associated with behavior in the safe zone

$\mathbf{I}_{2}$ second-order identity tensor
}

FT, DT, and NH stand for abbreviations of flow theory, deformation theory, and neo-Hookean model, respectively

\section{Constitutive equations}

\subsection{Geometric and mechanical assumptions}

For the modeling of strain localization in freestanding metal layers or in metal/elastomer bilayers, the following geometric and mechanical assumptions are considered:

\subsubsection{Geometric assumptions}

- A1: the metal layer and the elastomer layer are assumed to be thin.

- A2: the two layers remain perfectly bonded during the deformation.

\subsubsection{Mechanical assumptions for the metal layer}

- A3: for comparison purposes, the mechanical behavior of the metal layer will be modeled by two alternative constitutive frameworks: the flow theory of plasticity and the deformation theory counterpart.

- A4: the elasticity of the metal layer is neglected, which is justified by the fact that strain localization occurs at relatively large strains.

- A5: for both plasticity theories, the mechanical behavior is taken to be strain rate dependent. Because attention is restricted to materials characterized by isotropic hardening and isotropic plasticity, plastic anisotropy and kinematic hardening are not taken into account in the constitutive modeling.

\subsubsection{Mechanical assumptions for the elastomer layer}

- A6: the mechanical behavior of the elastomer layer is assumed to be incompressible and isotropic.

- A7: the mechanical response of the elastomer substrate is described by a hyperelastic neo-Hookean behavior model.

\subsection{Flow theory of plasticity}

Within this constitutive framework, plasticity is considered to be associative and the normality law applies. The combination of the associative plastic flow rule 
and assumption A4 in Section 2.1.2 leads to the following relation:

$\dot{\varepsilon}=\dot{\lambda} \frac{\partial \sigma_{\mathrm{eq}}}{\partial \sigma}$,

where $\dot{\varepsilon}, \dot{\lambda}, \sigma$, and $\sigma_{\text {eq }}$ are the strain rate tensor (the symmetric part of the Eulerian velocity gradient $\mathbf{G}$ ), the plastic multiplier, the Cauchy stress tensor, and the equivalent stress, respectively. As stated in assumption A5 (Section 2.1.2), plasticity is assumed to be isotropic and it is described by the von Mises criterion. Accordingly, the scalars $\dot{\lambda}$ and $\sigma_{\text {eq }}$ can be expressed as follows:

$\dot{\lambda}=\dot{\varepsilon}_{\mathrm{eq}}=\sqrt{(2 / 3) \dot{\varepsilon}: \dot{\varepsilon}} ; \quad \sigma_{\mathrm{eq}}=\sqrt{(3 / 2) \mathbf{S}: \mathbf{S}}$

where $\mathbf{S}$ is the deviatoric part of $\boldsymbol{\sigma}$.

The insertion of Eq. (2) into Eq. (1) allows deriving the following rigid-viscoplastic constitutive relation:

$\mathbf{S}=\frac{2 \sigma_{\mathrm{eq}}}{3 \dot{\varepsilon}_{\mathrm{eq}}} \dot{\varepsilon}$

Also, the equivalent stress $\sigma_{\text {eq }}$ can be related to the equivalent strain $\varepsilon_{\mathrm{eq}}$ and the equivalent strain rate $\dot{\varepsilon}_{\mathrm{eq}}$ via the Norton-Hoff viscoplasticity model

$\sigma_{\mathrm{eq}}=\mathrm{K} \varepsilon_{\mathrm{eq}}^{\mathrm{n}} \dot{\varepsilon}_{\mathrm{eq}}^{\mathrm{m}}$,

where $\mathrm{K}$ is a material parameter, $\mathrm{n}$ and $\mathrm{m}$ denote strain hardening and strain rate hardening exponents, respectively. Note that in Eq. (4), $\varepsilon_{\text {eq }}$ is the integral of $\dot{\varepsilon}_{\text {eq }}$ with respect to time.

\subsection{Deformation theory of plasticity}

The original formulation of the finite strain deformation theory of plasticity has been expressed in the frame of the principal strain directions, which coincides with the frame of the principal stress directions, as the behavior is assumed to be isotropic [5]. In this frame, the logarithmic strains $\varepsilon_{\mathrm{i}}$ can be related to the principal deviatoric stresses $\mathrm{S}_{\mathrm{i}}$ by the following relation:

$\mathrm{i}=1,2,3: \quad \mathrm{S}_{\mathrm{i}}=\frac{2 \sigma_{\mathrm{eq}}}{3 \varepsilon_{\mathrm{eq}}} \varepsilon_{\mathrm{i}}$.

In the above equation, $\sigma_{\text {eq }}$ has the same definition and the same expression as that used in the flow theory (Eq. $(2)_{2}$ ). However, the definition of $\varepsilon_{\text {eq }}$ is different from that used in the flow theory (Eq. (2) $)_{1}$. Indeed, in the deformation theory, $\varepsilon_{\text {eq }}$ is taken to be equal to $\sqrt{(2 / 3) \varepsilon_{\mathrm{i}} \varepsilon_{\mathrm{i}}}$.
Equation (5) has been subsequently extended in [6] to a tensorial form, which is valid for an arbitrary coordinate system

$\mathbf{S}=\frac{2}{3} \mathrm{E}_{\mathrm{S}} \ln \mathbf{V}$

where $E_{S}$ and $\ln \mathbf{V}$ are the secant modulus and the natural logarithmic of the left Cauchy-Green stretch tensor $\mathbf{V}$, respectively. The secant modulus $\mathrm{E}_{\mathrm{S}}$ is defined as

$\mathrm{E}_{\mathrm{S}}=\frac{\sigma_{\mathrm{eq}}}{\varepsilon_{\mathrm{eq}}}=\frac{3}{2} \sqrt{\frac{\mathbf{S}: \mathbf{S}}{\ln \mathbf{V}: \ln \mathbf{V}}}$

The Norton-Hoff model of Eq. (4) is still valid in the case of the deformation theory. It must be noted that similarly to $\varepsilon_{\text {eq }}$, the definition of $\dot{\varepsilon}_{\text {eq }}$ is different from that used in the flow theory. Indeed, in the case of the deformation theory, $\dot{\varepsilon}_{\mathrm{eq}}$ is simply defined as the time derivative of $\varepsilon_{\mathrm{eq}}$, the latter being equal to $\sqrt{(2 / 3) \varepsilon_{\mathrm{i}} \varepsilon_{\mathrm{i}}}$. In the case of proportional monotonic loading, the expressions of $\varepsilon_{\text {eq }}$, respectively $\dot{\varepsilon}_{\text {eq }}$, become equivalent for both plasticity theories.

For the Norton-Hoff model, the secant modulus $\mathrm{E}_{\mathrm{S}}$ is given by the following expression:

$\mathrm{E}_{\mathrm{S}}=\mathrm{K} \varepsilon_{\mathrm{eq}}^{\mathrm{n}-1} \dot{\varepsilon}_{\mathrm{eq}}^{\mathrm{m}}$.

The Cauchy stress tensor $\sigma$ can be derived from its deviatoric part $\mathbf{S}$, which is expressed in Eq. (3) for the flow theory and in Eq. (6) for the deformation theory, by

$\boldsymbol{\sigma}=\mathbf{S}+\mathrm{p} \mathbf{I}_{2}$

where $\mathrm{p}=(1 / 3) \operatorname{tr}(\sigma)$ is the hydrostatic pressure.

\subsection{Neo-Hookean model}

The mechanical behavior of the elastomer layer is defined by a neo-Hookean model [27, 28]

$\boldsymbol{\sigma}=\mu \mathbf{V}^{2}+\mathrm{q} \mathbf{I}_{2}$

where $\mu$ is the shear modulus, and $\mathrm{q}$ is an unknown pressure to be determined.

\section{Initial imperfection approach}

\subsection{Generic forms for the Cauchy stress and velocity gradient tensors}

We consider a quasi-static deformation state in a thin metal/ substrate bilayer (see assumption A1 in Section 2.1.1) induced by in-plane biaxial stretching. We define an orthogonal Cartesian coordinate system $\left(\overrightarrow{\mathbf{x}}_{1}, \overrightarrow{\mathbf{x}}_{2}, \overrightarrow{\mathbf{x}}_{3}\right)$, which is fixed 
to the bilayer as shown in Fig. 1, with axes $\overrightarrow{\mathbf{x}}_{1}$ and $\overrightarrow{\mathbf{x}}_{2}$ lying in the bilayer plane, and axis $\overrightarrow{\mathbf{x}}_{3}$ normal to this plane. Because the bilayer is sufficiently thin, it is justified to assume a planestress state [29]. This assumption is expressed by the following form of the Cauchy stress tensor $\sigma$ :

$$
\boldsymbol{\sigma}=\left(\begin{array}{ccc}
\sigma_{11} & \sigma_{12} & 0 \\
\sigma_{12} & \sigma_{22} & 0 \\
0 & 0 & 0
\end{array}\right)
$$

which is applicable to both the metal layer and the elastomer substrate.

Relation $\sigma_{33}=0$ allows us to determine the hydrostatic pressure p, introduced in Eq. (9), as well as the unknown pressure q involved in Eq. (10)

$\mathrm{p}=\mathrm{S}_{11}+\mathrm{S}_{22} \quad ; \mathrm{q}=-\mu \mathrm{V}_{33}^{2}$.

Equations (3), (6), and (10), in conjunction with Eq. (12), summarize the constitutive frameworks for the different material models used in this paper (i.e., flow theory, deformation theory, and neo-Hookean model) under the plane-stress condition. These equations will be coupled with those governing the initial imperfection approach (also designated as the Marciniak-Kuczynski (M-K) analysis in Section 3.2) to predict the FLDs of substrate-metal bilayers.

With regard to the constitutive relations of the different material models (see Eqs. (3), (6), and (10)), the plane-stress condition implies that the components 13, 23, 31, and 32 of the Eulerian velocity gradient $\mathbf{G}$ are equal to 0 . Hence, for the different layers and material models, $\mathbf{G}$ can be written in the following form:

$\mathbf{G}=\left(\begin{array}{ccc}\mathrm{G}_{11} & \mathrm{G}_{12} & 0 \\ \mathrm{G}_{21} & \mathrm{G}_{22} & 0 \\ 0 & 0 & \mathrm{G}_{33}\end{array}\right)$

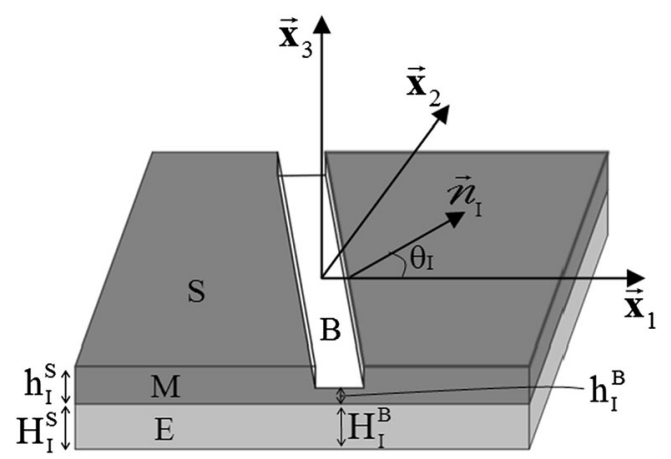

Fig. 1 Illustration of the $\mathrm{M}-\mathrm{K}$ analysis for a bilayer (initial geometry and band orientation)
Furthermore, in this work, all of the materials used are taken to be incompressible, which leads to

$\mathrm{G}_{33}=-\mathrm{G}_{11}-\mathrm{G}_{22}$.

By combining Eqs. (13) and (14), the velocity gradient $\mathbf{G}$ can be expressed in the following generic form:

$\mathbf{G}=\left(\begin{array}{ccc}\mathrm{G}_{11} & \mathrm{G}_{12} & 0 \\ \mathrm{G}_{21} & \mathrm{G}_{22} & 0 \\ 0 & 0 & -\mathrm{G}_{11}-\mathrm{G}_{22}\end{array}\right)$

\subsection{Governing equations for the initial imperfection approach}

Initially, a geometric non-uniformity in the form of a narrow band or neck is assumed to exist in the metal layer. As to the elastomer layer, it is assumed to be initially homogeneous. The initial configuration of the bilayer is depicted in Fig. 1.

The different notations used in Fig. 1 are explained in detail hereafter:

- $\mathrm{h}_{\mathrm{I}}^{\mathrm{B}}$ : initial thickness of the metal layer $\mathrm{M}$ inside the band B.

- $\mathrm{h}_{\mathrm{I}}^{\mathrm{S}}$ : initial thickness of the metal layer $\mathrm{M}$ in the safe zone $\mathrm{S}$ (outside the band).

- $\mathrm{H}_{\mathrm{I}}^{\mathrm{B}}$ : initial thickness of the elastomer layer $\mathrm{E}$ inside the band $\mathrm{B}$.

- $\mathrm{H}_{\mathrm{I}}^{\mathrm{S}}$ : initial thickness of the elastomer layer $\mathrm{E}$ in the safe zone $\mathrm{S}$ (outside the band).

- $\overrightarrow{\boldsymbol{n}}_{\mathrm{I}}$ : initial unit vector normal to the band.

- $\theta_{\mathrm{I}}$ : initial orientation of the band.

As a consequence of assumption A2 in Section 2.1.1, the velocity gradient of the metal layer remains equal to that of the elastomer layer throughout the deformation, in both the band and the safe zone:

$\mathbf{G}^{\mathrm{B}}(\mathrm{M})=\mathbf{G}^{\mathrm{B}}(\mathrm{E})=\mathbf{G}^{\mathrm{B}} \quad ; \quad \mathbf{G}^{\mathrm{S}}(\mathrm{M})=\mathbf{G}^{\mathrm{S}}(\mathrm{E})=\mathbf{G}^{\mathrm{S}}$

To predict FLDs, the sheet is loaded in the two-dimensional space (which maps the plane of the sheet) by applying inplane biaxial stretching along the directions of axes $\overrightarrow{\mathbf{x}}_{1}$ and $\overrightarrow{\mathbf{x}}_{2}$, as depicted in Fig. 1. Accordingly, the in-plane components of $\mathbf{G}^{\mathrm{S}}$ are given by the following relations:

$\frac{\mathrm{G}_{22}^{\mathrm{S}}}{\mathrm{G}_{11}^{\mathrm{S}}}=\rho=\mathrm{constan} \mathrm{t} \quad ; \quad \mathrm{G}_{12}^{\mathrm{S}}=\mathrm{G}_{21}^{\mathrm{S}}=0$.

The strain ratio $\rho$ will be assigned different values ranging from $-1 / 2$ (uniaxial tension) to 1 (equibiaxial expansion), in order to span the complete FLD. 
The insertion of Eqs. (17) into Eq. (15) leads to the following expression of the velocity gradient in the safe zone:

$\mathbf{G}^{\mathrm{S}}=\left[\begin{array}{ccc}\mathrm{G}_{11}^{\mathrm{S}} & 0 & 0 \\ 0 & \rho \mathrm{G}_{11}^{\mathrm{S}} & 0 \\ 0 & 0 & -(1+\rho) \mathrm{G}_{11}^{\mathrm{S}}\end{array}\right]$.

In addition to Eqs. (16) and (18), the following equations are used (which relate to compatibility, equilibrium, evolution of imperfection and band orientation...):
- The kinematic compatibility condition between the band and the safe zone, which allows us to express the jump in the velocity gradient across the band

$\mathbf{G}^{\mathrm{B}}=\mathbf{G}^{\mathrm{S}}+\dot{\overrightarrow{\mathbf{c}}} \otimes \overrightarrow{\boldsymbol{n}}$,

where $\dot{\overrightarrow{\mathbf{c}}}$ and $\overrightarrow{\boldsymbol{n}}$ are the jump vector and the current normal to the band, respectively. By inserting Eq. (18) into Eq. (19), one can derive the following expression for $\mathbf{G}^{\mathrm{B}}$ :

$\mathbf{G}^{\mathrm{B}}=\left[\begin{array}{ccc}\mathrm{G}_{11}^{\mathrm{S}}+\dot{\mathrm{c}}_{1} n_{1} & \dot{\mathrm{c}}_{1} n_{2} & 0 \\ \dot{\mathrm{c}}_{2} n_{1} & \rho \mathrm{G}_{11}^{\mathrm{S}}+\dot{\mathrm{c}}_{2} n_{2} & 0 \\ 0 & 0 & -(1+\rho) \mathrm{G}_{11}^{\mathrm{S}}-\dot{\mathrm{c}}_{1} n_{1}-\dot{\mathrm{c}}_{2} n_{2}\end{array}\right]$.

- The expressions of the initial and current imperfection ratios denoted as $\xi_{I}$ and $\xi$, respectively, are defined by

$\xi_{\mathrm{I}}=1-\frac{\mathrm{h}_{\mathrm{I}}^{\mathrm{B}}}{\mathrm{h}_{\mathrm{I}}^{\mathrm{S}}} \quad ; \quad \xi=1-\frac{\mathrm{h}^{\mathrm{B}}}{\mathrm{h}^{\mathrm{S}}}$.

The current thickness $h^{B}\left(\right.$ resp. $\left.h^{S}\right)$ is related to $h_{I}^{B}\left(\right.$ resp. $h_{I}^{S}$ ) by

$\mathrm{h}^{\mathrm{B}}=\mathrm{h}_{\mathrm{I}}^{\mathrm{B}} \mathrm{e}^{\varepsilon_{33}^{\mathrm{B}}} ; \mathrm{h}^{\mathrm{S}}=\mathrm{h}_{\mathrm{I}}^{\mathrm{S}} \mathrm{e}^{\varepsilon_{33}^{\mathrm{S}}}$,

where $\varepsilon_{33}^{\mathrm{B}}$ and $\varepsilon_{33}^{\mathrm{S}}$ are the 33 components of the logarithmic strain in the band and in the safe zone, respectively. By combining Eqs. (21) and (22), the ratios $\xi_{\mathrm{I}}$ of $\xi$ can be related by the following equation:

$\xi=1-\left(1-\xi_{\mathrm{I}}\right) \mathrm{e}^{\left(\varepsilon_{33}^{\mathrm{B}}-\varepsilon_{33}^{\mathrm{S}}\right)}$.

- The evolution of the band orientation is governed by the following equation:

$\operatorname{Tan}(\theta)=\mathrm{e}^{\left(\varepsilon_{11}^{\mathrm{s}}-\varepsilon_{22}^{\mathrm{s}}\right)} \operatorname{Tan}\left(\theta_{\mathrm{I}}\right)=\mathrm{e}^{(1-\rho) \varepsilon_{11}^{\mathrm{s}}} \operatorname{Tan}\left(\theta_{\mathrm{I}}\right)$.

- The equilibrium balance across the interface between the band and the safe zone can be expressed as follows:

$$
\left(\mathrm{h}^{\mathrm{B}} \boldsymbol{\sigma}^{\mathrm{B}}(\mathrm{M})+\mathrm{H}^{\mathrm{B}} \boldsymbol{\sigma}^{\mathrm{B}}(\mathrm{E})\right) \cdot \overrightarrow{\boldsymbol{n}}=\left(\mathrm{h}^{\mathrm{S}} \boldsymbol{\sigma}^{\mathrm{S}}(\mathrm{M})+\mathrm{H}^{\mathrm{S}} \boldsymbol{\sigma}^{\mathrm{S}}(\mathrm{E})\right) \cdot \overrightarrow{\boldsymbol{n}} .
$$

Note that this equilibrium equation implicitly assumes that the stress state is uniform over each layer in each zone.

- To solve the above equations, which govern the $\mathrm{M}-\mathrm{K}$ analysis, the constitutive equations are needed. These are given for both the metal layer and the elastomer substrate under the plane-stress conditions (see Eqs. (3), (6), (10), and (12)).

\section{Numerical implementation and algorithmic aspects}

\subsection{Implicit incremental algorithm for the FLD prediction}

The general algorithm used to predict the FLDs of metal/ elastomer bilayers is based on the following three nested loops:

- For $\rho=-1 / 2$ to $\rho=1$, at user-defined intervals (here, we take intervals of 0.1 ).

- For $\theta_{\mathrm{I}}$ spanning the admissible range of inclination angle (i.e., between $0^{\circ}$ and $90^{\circ}$ ), at user-defined intervals (here, we take intervals of $1^{\circ}$ ).

- For each time interval $\left[t_{n}, t_{n+1}\right]$ (with a time increment $\Delta \mathrm{t}=\mathrm{t}_{\mathrm{n}+1}-\mathrm{t}_{\mathrm{n}}$ ), apply the implicit incremental algorithm described in appendix $\bullet$ to integrate the governing equations pertaining to the metal and elastomer layers both in the safe zone and in the band. The application of this incremental integration scheme is stopped when the following criterion is satisfied:

$\mathrm{G}_{33}^{\mathrm{B}} / \mathrm{G}_{33}^{\mathrm{S}} \geq$ crit,

where "crit" is a positive threshold value set to 50 in the current investigation. The strain component $\varepsilon_{11}^{\mathrm{S}}$, thus obtained once criterion (26) is satisfied, is considered to be the critical strain $\varepsilon_{11}^{*}$ corresponding to the current band inclination $\theta$ and strain-path ratio $\rho$. 
The lowest critical strain $\varepsilon_{11}^{*}$, solution of the above algorithm, over all initial angles $\theta_{\mathrm{I}}$ and the corresponding current angle define, respectively, the necking limit strain $\varepsilon_{11}^{\mathrm{L}}$ and the necking band orientation for the current strain-path ratio $\rho$.

The present algorithm has been implemented using the multi-paradigm numerical computing environment Matlab (R2015).

\section{Numerical results}

This section is divided into two subsections. The first one is dedicated to the freestanding metal layer results, where we revisit some well-known literature results $[9,11]$. The second subsection is devoted to the bilayer results, which represent the main novelties in this paper. For the different simulations, the hardening parameter $\mathrm{K}$ of the metal layer is set to $1000 \mathrm{MPa}$.
Fig. 2 Evolution of the ratio $\varepsilon_{11}^{\mathrm{B}}$ $/ \varepsilon_{11}^{\mathrm{S}}$ as a function of $\varepsilon_{11}^{\mathrm{S}}$ for a freestanding metal layer $\left(\xi_{\mathrm{I}}=5 \times\right.$ $\left.10^{-3}\right): \mathbf{a} \rho=-0.5, \theta_{\mathrm{I}}=20^{\circ}$, and $\mathrm{n}=0.1 ; \mathbf{b} \rho=-0.5, \theta_{\mathrm{I}}=20^{\circ}$, and $\mathrm{n}=0.4 ; \mathbf{c} \rho=0, \theta_{\mathrm{I}}=0^{\circ}$, and $\mathrm{n}=$ $0.1 ; \mathbf{d} \rho=0, \theta_{\mathrm{I}}=0^{\circ}$, and $\mathrm{n}=0.4 ; \mathbf{e}$ $\rho=1, \theta_{\mathrm{I}}=0^{\circ}$, and $\mathrm{n}=0.1 ; \mathbf{f} \rho=1$, $\theta_{\mathrm{I}}=0^{\circ}$, and $\mathrm{n}=0.4$

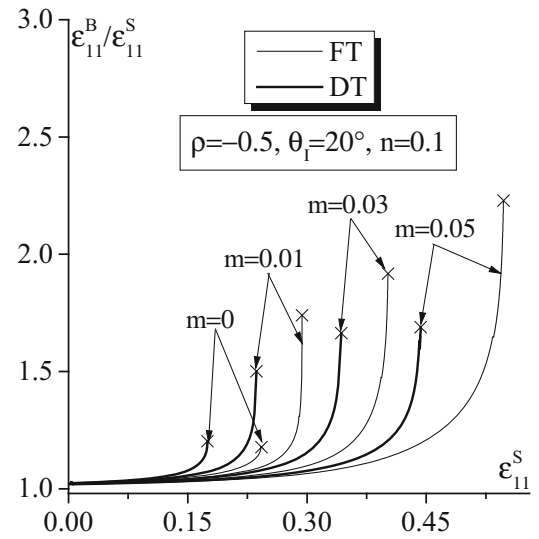

(a)

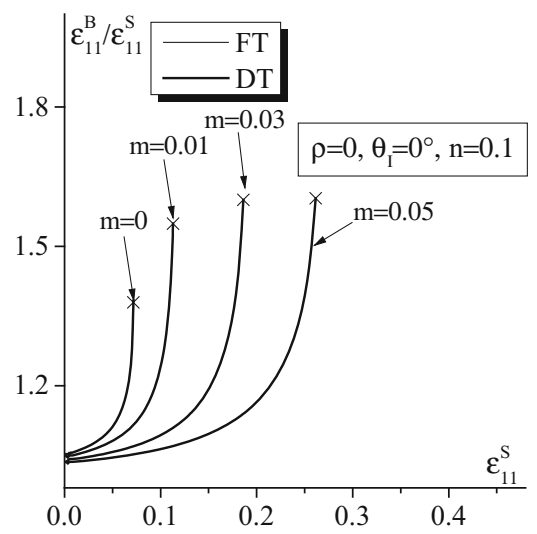

(c)

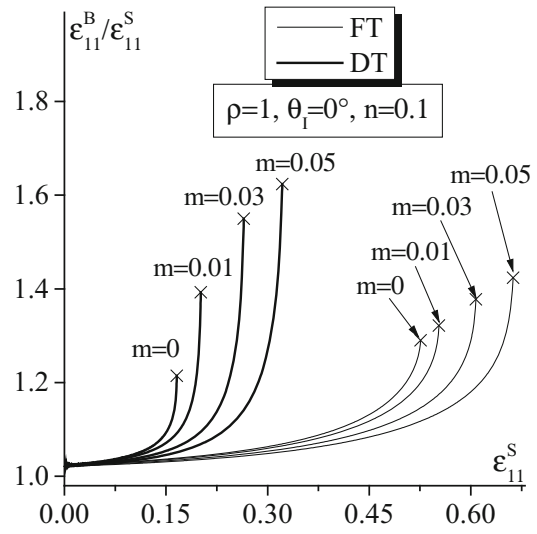

(e)

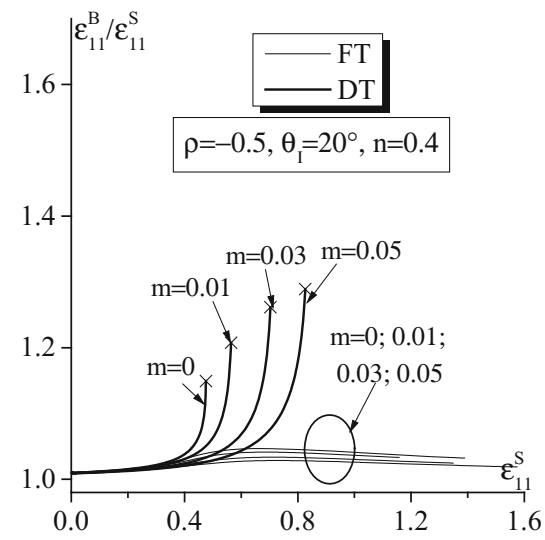

(b)

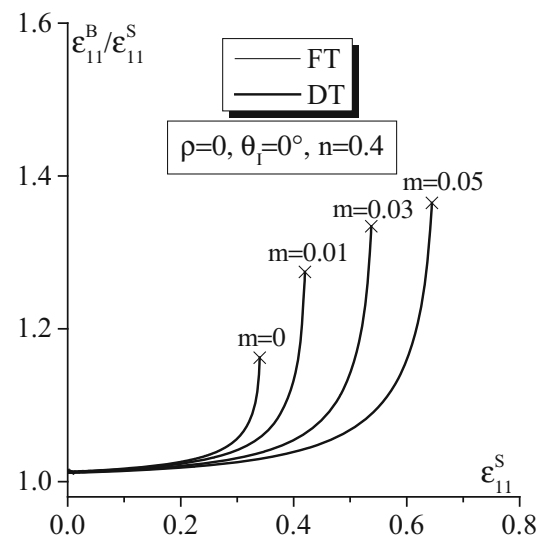

(d)

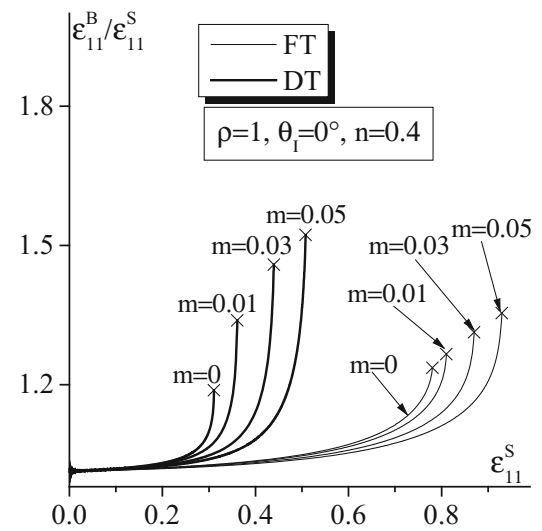

(f) 


\subsection{Freestanding metal layer}

Reference to the metal or elastomer layer is obviously omitted in this section, as only a freestanding metal layer is studied here. To first emphasize the respective effects of hardening exponent $\mathrm{n}$ and strain rate sensitivity $\mathrm{m}$ on necking retardation, the evolution of the ratio $\varepsilon_{11}^{\mathrm{B}} / \varepsilon_{11}^{\mathrm{S}}$ as a function of the strain component $\varepsilon_{11}^{\mathrm{S}}$ is depicted in Fig. 2 for two different values of $n(0.1$ and 0.4$)$ and four different values of $m(0$, $0.01,0.03$, and 0.05$)$. Three representative strain paths ( $\rho=-$ $1 / 2, \rho=0$, and $\rho=1)$ are used in the simulations reported in Fig. 2. The initial band orientation $\theta_{\mathrm{I}}$ is set to $20^{\circ}$ for the first strain path and to $0^{\circ}$ for the two other strain paths. It should be clarified that these values do not necessarily correspond to the initial band orientations that are associated with the limit strains. This is especially the case for the uniaxial tension state in Fig. 2a, b. The initial geometric imperfection ratio $\xi_{I}$ is set to $5 \times 10^{-3}$ for all of the simulations reported in Fig. 2. The computations are stopped when the necking criterion (26) is satisfied. Accordingly, the cross tagged at the end of each curve indicates the magnitude of the predicted critical strain $\varepsilon_{11}^{*}$. As can be seen in Fig. 2, at the beginning of deformation, the ratio $\varepsilon_{11}^{\mathrm{B}} / \varepsilon_{11}^{\mathrm{S}}$ is very close to 1 . At the incipience of localized necking, $\varepsilon_{11}^{\mathrm{B}}$ increases rapidly compared to $\varepsilon_{11}^{\mathrm{S}}$. It is clear from the different curves that the predicted critical strain $\varepsilon_{11}^{*}$ substantially increases both with the strain rate sensitivity parameter and with the strain hardening exponent. Other conclusions can be drawn from Fig. 2, which are specific to the strain path considered:

- Uniaxial tension state: it can be seen that, for a strain hardening exponent $\mathrm{n}$ equal to 0.1 , the critical strains predicted by the flow theory of plasticity are finite and are always higher than their counterparts predicted by the deformation theory (see Fig. 2a). However, when the hardening exponent $\mathrm{n}$ is set to 0.4 (Fig. 2b), the critical strains predicted by the flow theory are infinite. Indeed, $\varepsilon_{11}^{\mathrm{S}}$ remains close to $\varepsilon_{11}^{\mathrm{B}}$ and the threshold value, determined by the numerical criterion (26), cannot be reached in this case.

- Plane-strain tension state: both plasticity models provide the same results for this particular strain path, regardless of the values of the strain rate sensitivity $m$ and the strain hardening exponent $\mathrm{n}$, as demonstrated by Fig. 2c, d. Indeed, the evolution of the ratio $\varepsilon_{11}^{\mathrm{B}} / \varepsilon_{11}^{\mathrm{S}}$ as a function of $\varepsilon_{11}^{\mathrm{S}}$ is exactly the same for both plasticity theories. Accordingly, for this particular strain path, the predicted
Fig. 3 Impact of strain rate sensitivity on the retardation of necking for a freestanding metal layer and different initial imperfection ratios: a FT, $\rho=0$, $\theta_{\mathrm{I}}=0^{\circ} ; \mathbf{b}$ DT, $\rho=0, \theta_{\mathrm{I}}=0^{\circ} ; \mathbf{c}$ FT, $\rho=1, \theta_{\mathrm{I}}=0^{\circ} ; \mathbf{d}$ DT, $\rho=1, \theta_{\mathrm{I}}=0$

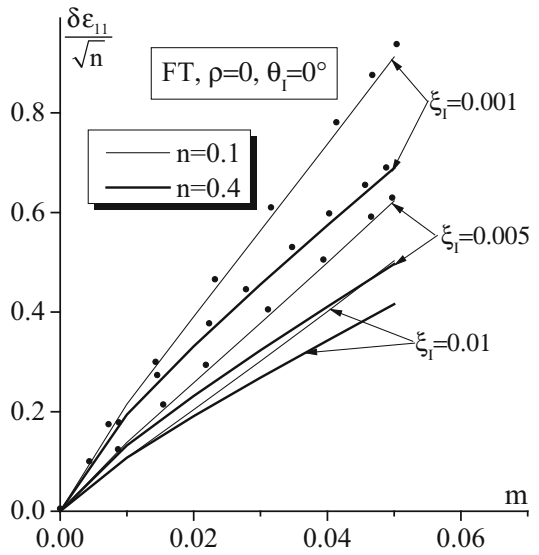

(a)

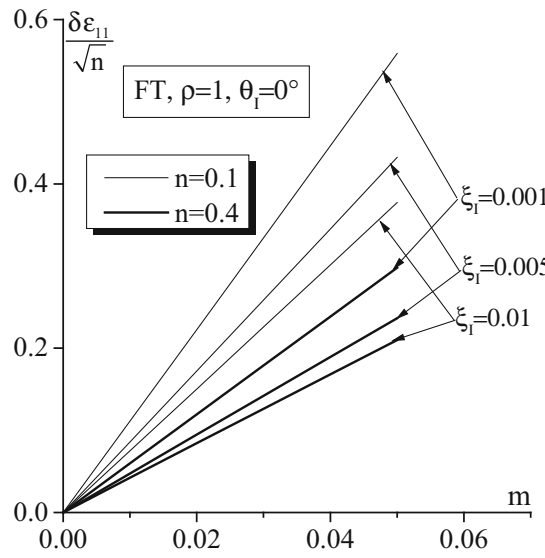

(c)

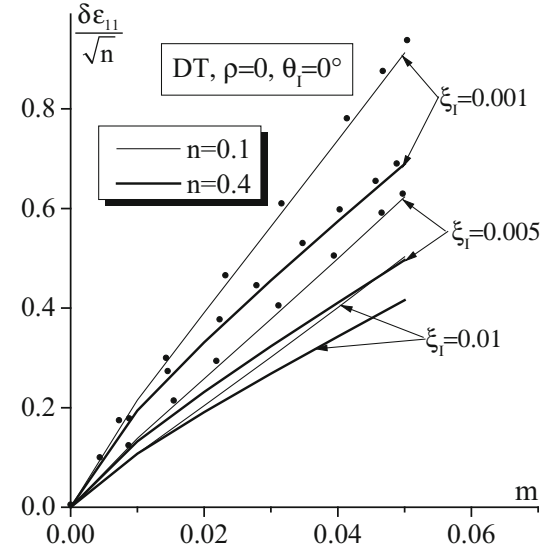

(b)

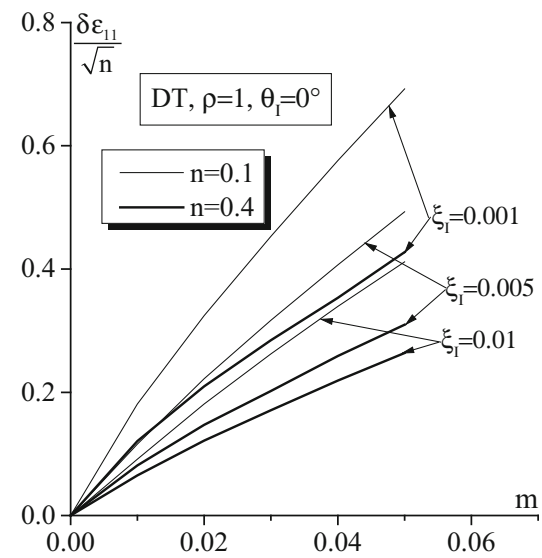

(d) 
limit strains are independent of the plasticity theory used to model the material behavior (i.e., flow theory or deformation theory). This is due to the fact that the strain path remains linear (a plane-strain state) along deformation in both zones (i.e., the safe zone and the band). Because the initial band orientation $\theta_{\mathrm{I}}$ is set to 0 , the current band orientation $\theta$ and the unit vector $\overrightarrow{\boldsymbol{n}}$ normal to the band remain equal to 0 and $(1,0,0)$, respectively, during the deformation. Hence, the equilibrium Eq. (25) reduces to

$\mathrm{h}^{\mathrm{B}} \sigma_{11}^{\mathrm{B}}=\mathrm{h}^{\mathrm{S}} \sigma_{11}^{\mathrm{S}}$.

Because the strain path is linear, $\sigma_{11}^{\mathrm{B}}$, respectively, $\sigma_{11}^{\mathrm{S}}$ has the same expression for the flow theory and the deformation theory

$$
\begin{aligned}
& \sigma_{11}^{\mathrm{B}}=\left(\frac{2}{\sqrt{3}}\right)^{\mathrm{n}+\mathrm{m}+1} \mathrm{~K}\left(\varepsilon_{11}^{\mathrm{B}}\right)^{\mathrm{n}}\left(\dot{\varepsilon}_{11}^{\mathrm{B}}\right)^{\mathrm{m}} ; \\
& \sigma_{11}^{\mathrm{S}}=\left(\frac{2}{\sqrt{3}}\right)^{\mathrm{n}+\mathrm{m}+1} \mathrm{~K}\left(\varepsilon_{11}^{\mathrm{S}}\right)^{\mathrm{n}}\left(\dot{\varepsilon}_{11}^{\mathrm{S}}\right)^{\mathrm{m}} .
\end{aligned}
$$

Accordingly, Eq. (27) can be rewritten as

$$
\mathrm{h}_{\mathrm{I}}^{\mathrm{B}} \mathrm{e}^{\varepsilon_{33}^{\mathrm{B}}}\left(\varepsilon_{11}^{\mathrm{B}}\right)^{\mathrm{n}}\left(\Delta \varepsilon_{11}^{\mathrm{B}}\right)^{\mathrm{m}}=\mathrm{h}_{\mathrm{I}}^{\mathrm{S}} \mathrm{e}^{\varepsilon_{33}^{\mathrm{S}}}\left(\varepsilon_{11}^{\mathrm{S}}\right)^{\mathrm{n}}\left(\Delta \varepsilon_{11}^{\mathrm{S}}\right)^{\mathrm{m}} .
$$

Fig. 4 Evolution of the limit strain $\varepsilon_{11}^{\mathrm{L}}$ with the initial imperfection ratio $\xi_{\mathrm{I}}$ for a freestanding metal layer $(\mathrm{n}=0.4)$ : a $\rho=-0.5, \mathbf{b} \rho=0, \mathbf{c} \rho=0.5, \mathbf{d}$ $\rho=1$
Making use of Eq. (21), and taking into account the planestrain character of the strain path (i.e., $\varepsilon_{33}^{\mathrm{B}}$ and $\varepsilon_{33}^{\mathrm{S}}$ being equal to $-\varepsilon_{11}^{\mathrm{B}}$ and $-\varepsilon_{11}^{\mathrm{S}}$, respectively), Eq. (29) can be rewritten as

$$
\left(1-\xi_{\mathrm{I}}\right) \mathrm{e}^{-\varepsilon_{11}^{\mathrm{B}}}\left(\varepsilon_{11}^{\mathrm{B}}\right)^{\mathrm{n}}\left(\Delta \varepsilon_{11}^{\mathrm{B}}\right)^{\mathrm{m}}=\mathrm{e}^{-\varepsilon_{11}^{\mathrm{S}}}\left(\varepsilon_{11}^{\mathrm{S}}\right)^{\mathrm{n}}\left(\Delta \varepsilon_{11}^{\mathrm{S}}\right)^{\mathrm{m}} .
$$

This latter relation is valid for both the flow theory and the deformation theory of plasticity. The results reported in Fig. 2c, d are obtained by incrementally solving Eq. (30), in which the input increment $\Delta \varepsilon_{11}^{\mathrm{B}}$ is set to $10^{-3}$ and the main unknown is $\Delta \varepsilon_{11}^{\mathrm{S}}$.

The predicted evolutions are in agreement with the previously reported literature results [8,9]. Furthermore, it is worth noting that, in the case of no strain rate sensitivity (i.e., $\mathrm{m}=0$ ), the corresponding evolutions coincide with those obtained with the rate-independent version of the above-described constitutive models [6].

- Equibiaxial tension state: much larger differences between the predictions of the flow theory and those of the deformation theory are observed in Fig. 2e, f. Indeed, the limit strains predicted by flow theory are substantially higher than those based on the deformation theory of plasticity.

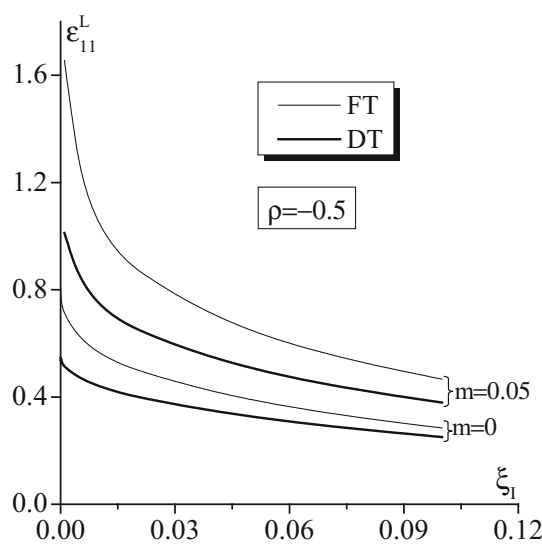

(a)

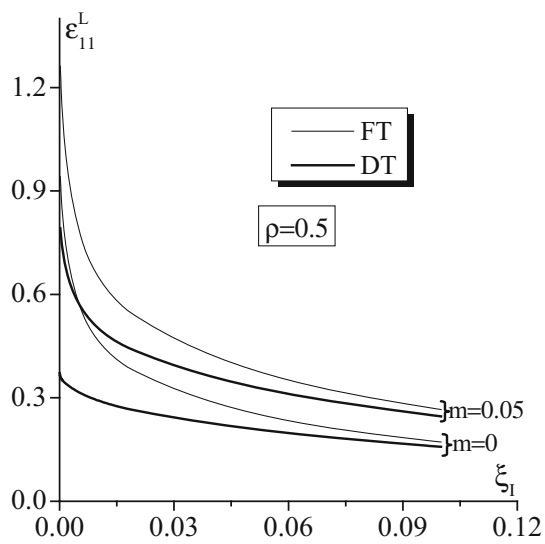

(c)

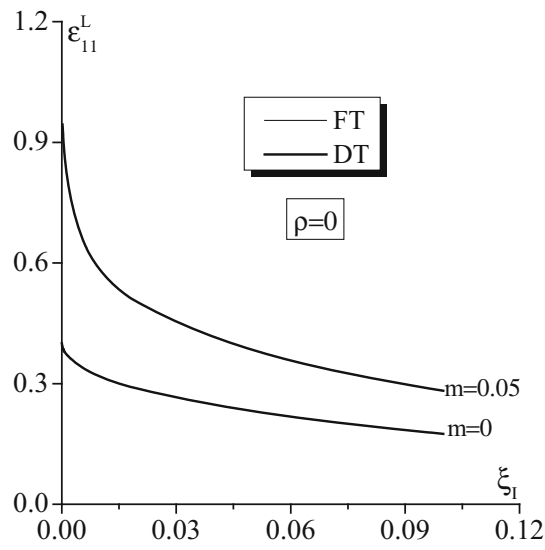

(b)

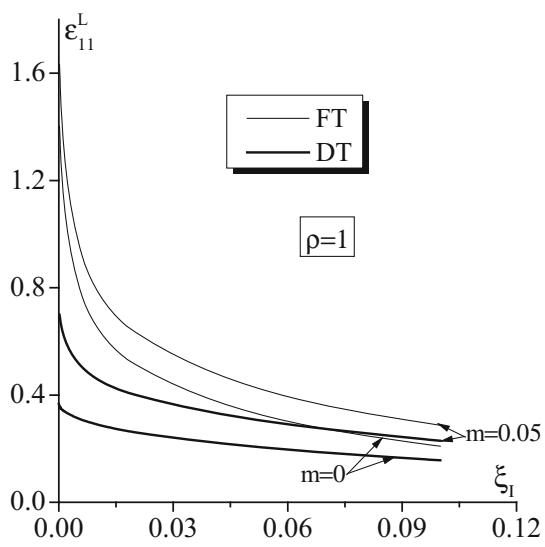

(d) 
Table 1 Values of the predicted limit strains $\varepsilon_{11}^{\mathrm{L}}$ in the case of a sheet metal with no initial imperfection $\left(\xi_{\mathrm{I}}=0\right)$

\begin{tabular}{llllll}
\hline & & $\rho=-1 / 2$ & $\rho=0$ & $\rho=1 / 2$ & $\rho=1$ \\
\hline Flow theory & $\mathrm{m}=0$ & $\mathrm{n} /(1+\rho)=0.8$ & $\mathrm{n} /(1+\rho)=0.4$ & $\infty$ & $\infty$ \\
& $\mathrm{m}=0.05$ & $\infty$ & $\infty$ & $\infty$ & $\infty$ \\
Deformation theory & $\mathrm{m}=0$ & 0.54 & $\mathrm{n} /(1+\rho)=0.4$ & 0.37 & 0.36 \\
& $\mathrm{~m}=0.05$ & $\infty$ & $\infty$ & $\infty$ & $\infty$ \\
\hline
\end{tabular}

To further investigate the impact of strain rate sensitivity on the onset of localized necking, the necking retardation factor $\delta \varepsilon_{11}$, defined as $\delta \varepsilon_{11}=\varepsilon_{11}^{\mathrm{L}}-\left.\varepsilon_{11}^{\mathrm{L}}\right|_{\mathrm{m}=0}$, normalized by $\sqrt{\mathrm{n}}$, is plotted as a function of the $m$ exponent in Fig. 3. Obviously, $\delta \varepsilon_{11}$ is equal to 0 for strain rate-independent materials. For most common sheet metals at room temperature, the typical values for $m$ range between 0 and 0.05 . Accordingly, values of $\mathrm{m}$ in the same range are considered in the present simulations. In order to investigate the respective effects of strain rate sensitivity and initial imperfection on necking retardation, three values for $\xi_{\mathrm{I}}$ are used in the simulations: $10^{-3}, 5 \times 10^{-3}$, and $10^{-2}$. The simulation results obtained by the developed numerical tool are represented by solid curves in Fig. 3, in comparison with the available results published in [11], which are represented by dotted graphs with symbols $(\bullet)$. It is clear that both results match very well, thus providing at least a partial validation of the developed tool. The different curves plotted in Fig. 3 confirm the trends observed in Fig. 2 with regard to the substantial role of strain rate sensitivity in increasing the potential of straining prior to necking. Indeed, small values for $\mathrm{m}$ are sufficient to produce noticeable retardation of necking. Figure $3 \mathrm{a}, \mathrm{b}$ show that, for the case of plane-strain tension, both plasticity theories predict exactly the same evolution for $\delta \varepsilon_{11} / \sqrt{n}$ as a function of m. Also, all the curves in Fig. 3 demonstrate that, for both strain paths and plasticity theories considered, the necking retardation increases as the strain hardening exponent $\mathrm{n}$ decreases. As to the impact of the initial geometric imperfection $\xi_{I}$ on necking retardation, it can be clearly seen that factor $\delta \varepsilon_{11} / \sqrt{\mathrm{n}}$ is inversely proportional to $\xi_{\text {I }}$. In other words, $\delta \varepsilon_{11} / \sqrt{\mathrm{n}}$ becomes infinite when $\xi_{\mathrm{I}}$ approaches 0 . This latter result is consistent with the fact that without introducing an initial geometric imperfection, the
Fig. 5 Evolution of the critical strain $\varepsilon_{11}^{*}$ as a function of the band orientation $\theta$ for a freestanding metal layer $(\rho=-0.5): \mathbf{a} \xi_{\mathrm{I}}=$ $10^{-3}, \mathrm{n}=0.22 ; \mathbf{b} \xi_{\mathrm{I}}=10^{-2}, \mathrm{n}=$ $0.22 ; \mathbf{c} \xi_{\mathrm{I}}=10^{-3}, \mathrm{n}=0.5 ; \mathbf{d} \xi_{\mathrm{I}}=$ $10^{-2}, \mathrm{n}=0.5$

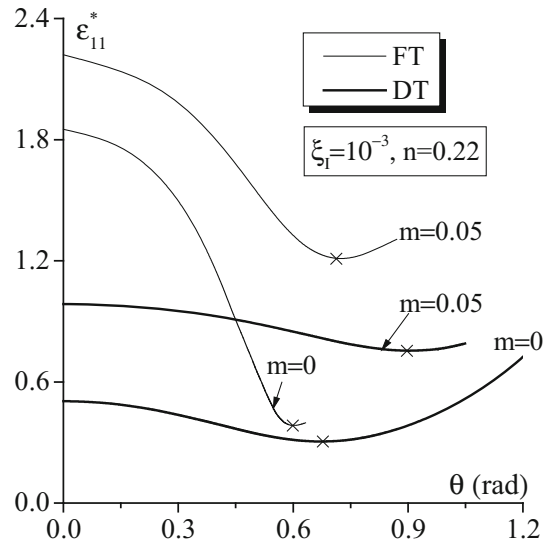

(a)

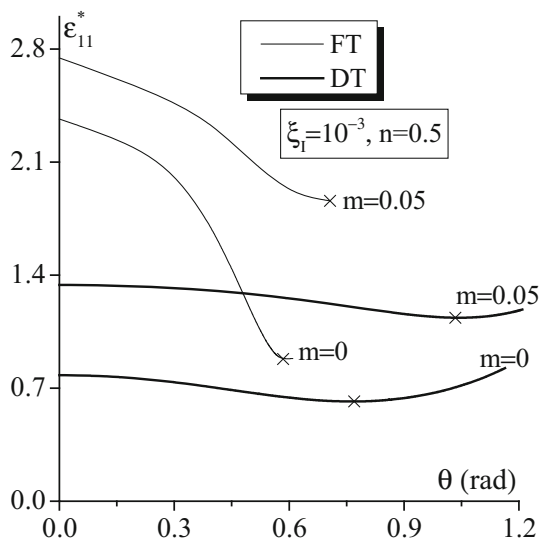

(c)

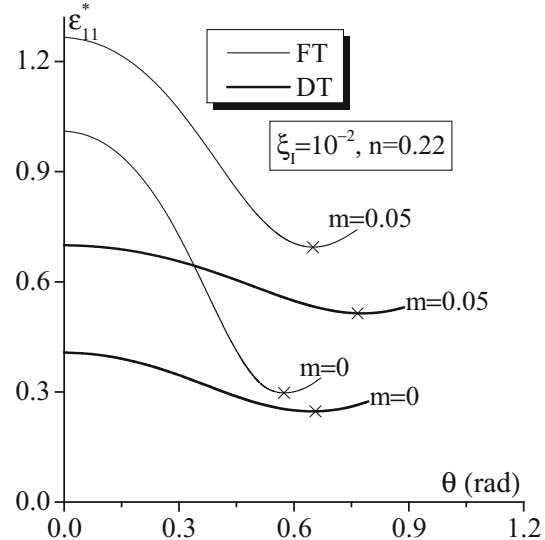

(b)

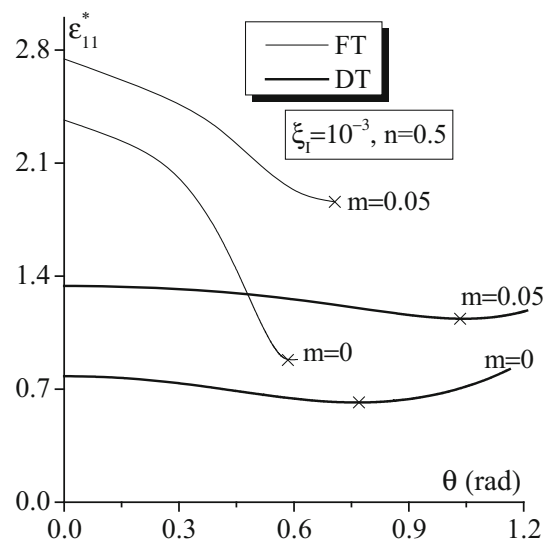

(d) 
numerical predictions of limit strains based on a strain ratedependent model lead to infinite values [9, 11]. These preliminary results will be carefully analyzed and commented in the following section.

The effect of the initial geometric imperfection $\xi_{\text {I }}$ on the limit strain $\varepsilon_{11}^{\mathrm{L}}$ for four representative strain paths $(\rho=-1 / 2, \rho=0, \rho=1 / 2$, and $\rho=1)$ is reflected in Fig. 4. In these simulations, the hardening exponent $n$ is set to 0.4 and two different values for $\mathrm{m}$ are considered: 0 and 0.05 . From the different curves depicted in Fig. 4, it can be seen that a relatively small imperfection significantly reduces the magnitude of the limit strains. Indeed, a geometric imperfection has a destabilizing role, which precipitates the occurrence of strain localization. Furthermore, as revealed by the different curves, the necking retardation factor $\delta \varepsilon_{11}$ decreases as the initial imperfection $\xi_{I}$ increases, thus confirming the results of Fig. 3. By comparing both plasticity theories, it appears that the predictions obtained with the flow theory of plasticity are more sensitive to the initial geometric imperfection than those given by the deformation theory, especially in the biaxial loading range. Other important conclusions, related to strain rate sensitivity, can be drawn in what follows:
- Strain rate-independent material $(\mathrm{m}=0)$ : for the uniaxial tension state, the limit strain $\varepsilon_{11}^{\mathrm{L}}$ approaches a finite value when the initial imperfection ratio tends to zero. In this case, the obtained limit strain value is 0.8 (resp. 0.54) for flow theory (resp. deformation theory). Furthermore, it can be noted that for plane-strain tension, both the flow theory and the deformation theory predict the same evolution for $\varepsilon_{11}^{\mathrm{L}}$ as a function of $\xi_{\mathrm{I}}$ (see Fig. 4b). These trends confirm the results obtained in Fig. 2c, d. Besides, when $\xi_{\mathrm{I}}$ vanishes, the limit strain $\varepsilon_{11}^{\mathrm{L}}$ determined by the flow theory satisfies the relation $\varepsilon_{11}^{\mathrm{L}}=\mathrm{n} /(1+\rho)$, in the case of uniaxial tension and plane-strain tension. It is worth noting that the latter result is consistent with the theoretical predictions given by Hill's localized necking criterion [3]. For positive strain paths $(\rho=1 / 2$ and $\rho=1)$, when the flow theory is applied, the introduction of an initial imperfection is required to obtain finite values for $\varepsilon_{11}^{\mathrm{L}}$, as demonstrated in Fig. $4 c$, d. Indeed, in this case, $\varepsilon_{11}^{\mathrm{L}}$ tends to infinity as $\xi_{I}$ tends to zero. By contrast, when $\xi_{I}$ vanishes, the strain rate-independent deformation theory of plasticity predicts finite values for $\varepsilon_{11}^{\mathrm{L}}$, even in the range of positive strain paths. This latter result is the consequence of the destabilizing vertex effects, which are inherent to the
Fig. 6 Evolution of the band orientation for a freestanding metal layer and different values for the strain rate sensitivity parameter: a $\xi_{\mathrm{I}}=10^{-3}, \mathrm{n}=0.22 ; \mathbf{b}$ $\xi_{\mathrm{I}}=10^{-2}, \mathrm{n}=0.22 ; \mathbf{c} \xi_{\mathrm{I}}=10^{-3}$, $\mathrm{n}=0.5 ; \mathbf{d} \xi_{\mathrm{I}}=10^{-2}, \mathrm{n}=0.5$

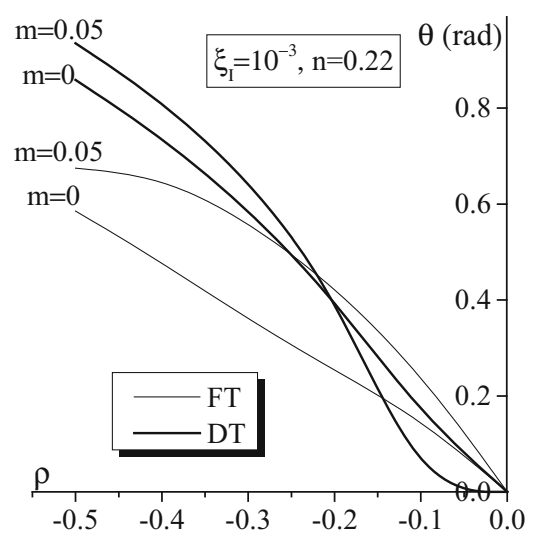

(a)

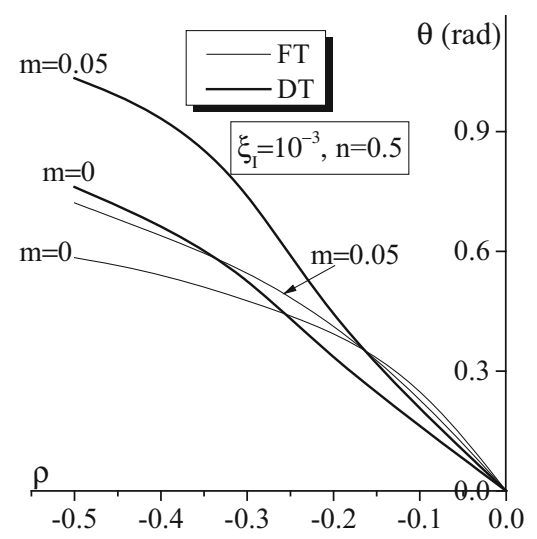

(c)

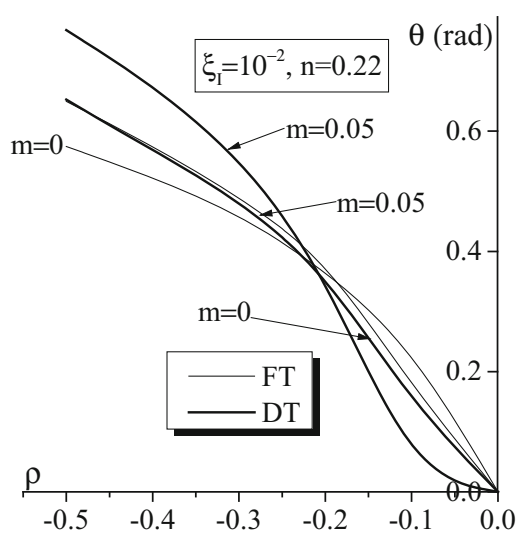

(b)

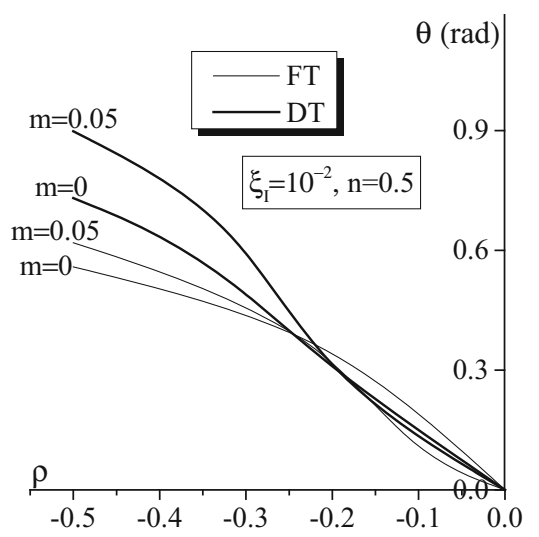

(d) 
deformation theory of plasticity $[4,5]$. It is nowadays well-known that these yield surface vertex effects have a destabilizing role in promoting and precipitating early plastic instabilities.

- Strain rate-dependent material $(\mathrm{m}=0.05)$ : in this case, the predicted limit strains show high sensitivity to the initial imperfection factor $\xi_{\mathrm{I}}$, because, as stated earlier, $\varepsilon_{11}^{\mathrm{L}}$ becomes infinite when $\xi_{\text {I }}$ tends towards zero. In other words, bifurcation is ruled out in rate-sensitive materials, and this result applies for all strain paths and for both theories of plasticity.

Table 1 reports the predicted values for $\varepsilon_{11}^{\mathrm{L}}$, in the case of a sheet metal with no initial imperfection $\left(\xi_{\mathrm{I}}=0\right)$, as determined by both plasticity theories.

Figure 5 shows the evolution of the critical strain $\varepsilon_{11}^{*}$ as a function of the band orientation $\theta$ (at the onset of necking) for the uniaxial tensile state. The crosses reported on the different curves indicate the value of the limit strain $\varepsilon_{11}^{\mathrm{L}}$ and the associated necking band orientation. It should be recalled that the limit strain $\varepsilon_{11}^{\mathrm{L}}$ is obtained by minimizing the critical strains $\varepsilon_{11}^{*}$ over all possible band orientations. It can be observed that, regardless of the strain rate sensitivity value $m$, the critical strains predicted by the flow theory of plasticity are much more sensitive to the variation of $\theta$ than those obtained with the deformation theory. Indeed, the critical strains predicted by the deformation theory are rather unaffected by small changes in $\theta$. Furthermore, it can be seen that, for both plasticity theories, the value of the necking band orientation $\theta$ that minimizes the critical strain $\varepsilon_{11}^{*}$ increases as the strain rate hardening exponent increases. The effect of the initial imperfection $\xi_{\text {I }}$ on the necking band orientation is not very noticeable from the curves in Fig. 5.

Further investigations on the effect of strain rate sensitivity on the necking band orientation are reported in Fig. 6. In this figure, the evolution of $\theta$ as a function of the strain path $\rho$ is plotted for two hardening exponents $(0.22$ and 0.5$)$ and for two initial imperfection ratios $\left(10^{-3}\right.$ and $\left.10^{-2}\right)$. In the biaxial tension range $(\rho \geq 0)$, the band orientation $\theta$ that minimizes the critical strain is equal to 0 . In other words, the necking band is always perpendicular to the major strain direction for positive strain paths. Accordingly, the evolution of $\theta$ is only presented for the negative range of strain paths. It is revealed that the dependence of the necking band orientation on the strain rate sensitivity is generally function of the strain-path range considered. For strain paths in the neighborhood of the uniaxial tensile state, the value of necking band orientation increases with $\mathrm{m}$. The opposite trend is observed for strain
Fig. 7 Effect of the strain rate sensitivity parameter $\mathrm{m}$ and the initial imperfection ratio $\xi_{\mathrm{I}}$ on the shape and the location of the FLDs for a freestanding metal layer: a flow theory, $\mathrm{n}=0.22 ; \mathbf{b}$ deformation theory, $\mathrm{n}=0.22$; $\mathbf{c}$ flow theory, $\mathrm{n}=0.5 ; \mathbf{d}$ deformation theory, $\mathrm{n}=0.5$

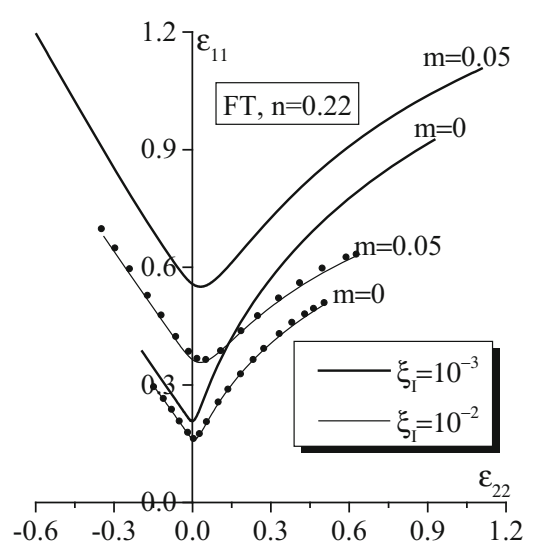

(a)

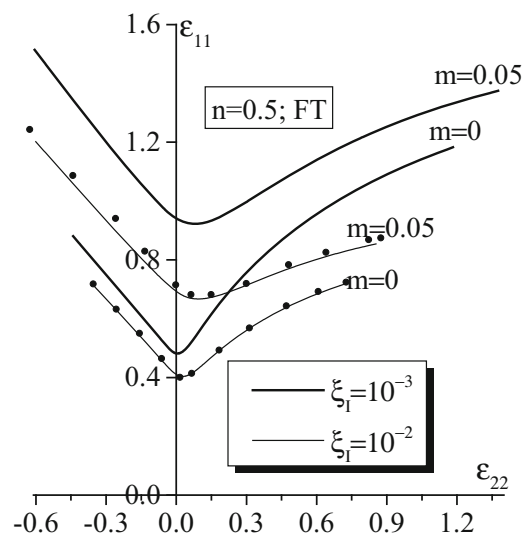

(c)

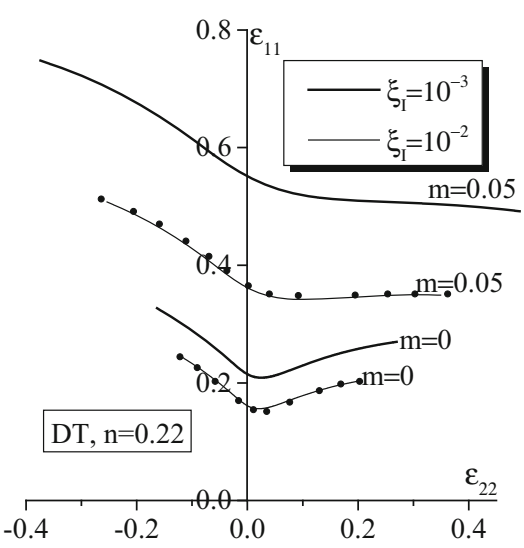

(b)

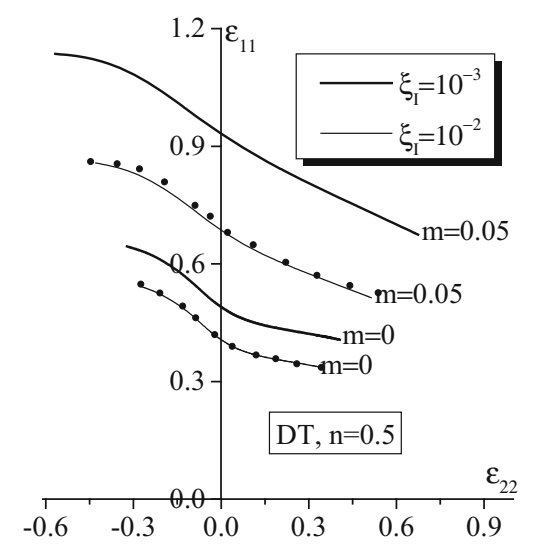

(d) 
paths close to plane-strain tension. Also, the necking band orientation increases when the initial imperfection ratio decreases, as demonstrated in Fig. 6.

The respective effect of strain rate sensitivity and initial imperfection ratio on the shape and location of the predicted FLDs is investigated in Fig. 7. More specifically, a comparative analysis is conducted for the predictions given by both plasticity theories for two values of $\mathrm{m}(0$ and 0.05$)$ and two values of $\xi_{\mathrm{I}}\left(10^{-3}\right.$ and $\left.10^{-2}\right)$. In view of these results, the following conclusions may be drawn:
- Compared to the case of strain rate-independent material behavior $(m=0)$, the strain rate sensitivity substantially increases the value of the predicted limit strain $\varepsilon_{11}^{\mathrm{L}}$ for all of the strain paths considered (i.e., ranging from uniaxial tension to equibiaxial expansion). Indeed, it can be seen that the effect of strain rate sensitivity is essentially to shift the FLD monotonically upwards, and thus to significantly enhance the ductility of the freestanding metal layer.

- With respect to the reference FLD associated with strain rate-independent material behavior, the shape of the FLD
Fig. 8 Evolution of $\varepsilon_{11}^{\mathrm{B}} / \varepsilon_{11}^{\mathrm{S}}$ as a function of $\varepsilon_{11}^{\mathrm{S}}$ for a metal/ elastomer bilayer and different values for the strain rate sensitivity parameter $\left(\xi_{I}=10^{-2}\right)$ : a FT/NH, $\rho=-0.5, \theta_{\mathrm{I}}=15^{\circ} ; \mathbf{b}$ $\mathrm{DT} / \mathrm{NH}, \rho=-0.5, \theta_{\mathrm{I}}=15^{\circ} ; \mathbf{c ~ F T} /$ NH, $\rho=0, \theta_{\text {I }}=0^{\circ} ; \mathbf{d}$ DT $/ \mathrm{NH}, \rho=$ $0, \theta_{\mathrm{I}}=0^{\circ} ; \mathbf{e ~ F T / N H ,} \rho=1, \theta_{\mathrm{I}}=0^{\circ}$; f DT/NH, $\rho=1, \theta_{\mathrm{I}}=0^{\circ}$

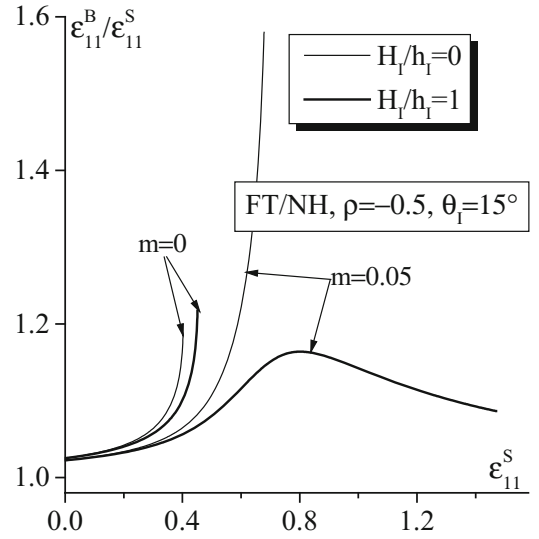

(a)

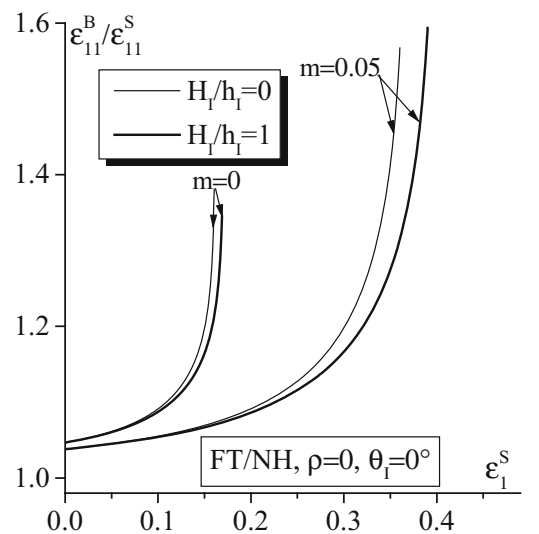

(c)

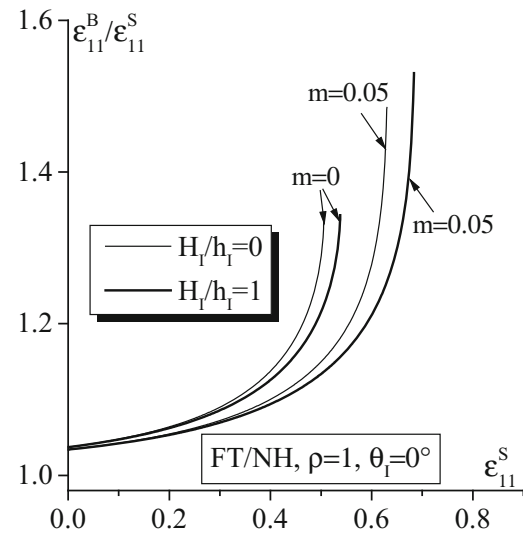

(e)

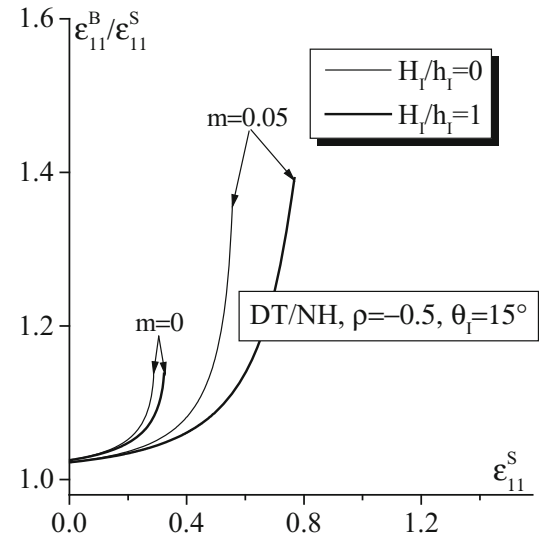

(b)

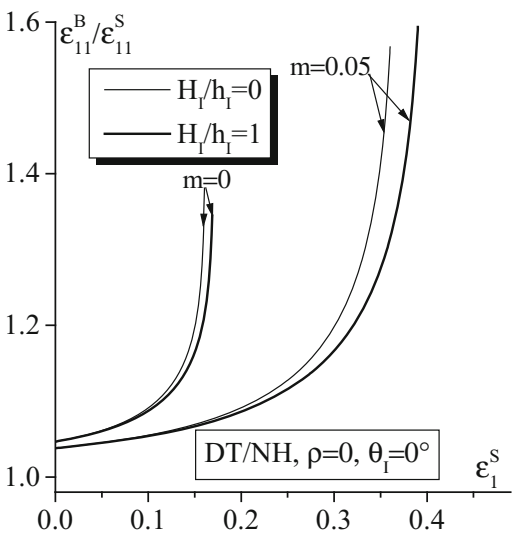

(d)

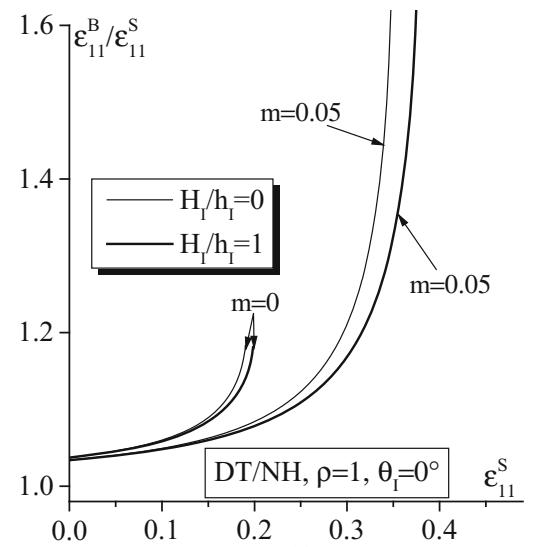

(f) 
is slightly altered by strain rate sensitivity, especially in the range of positive strain paths.

- The FLDs predicted by the deformation theory of plasticity are less sensitive to initial imperfections as compared to those predicted by the flow theory, especially in the range of positive strain paths. This trend confirms the results previously discussed in Fig. 4.

- Contrarily to the flow theory of plasticity, the FLDs predicted by the deformation theory correspond to more realistic strain levels, irrespective of the value of strain rate sensitivity.

- In the particular case of plane-strain tension $(\rho=0)$, the limit strains based on the deformation theory of plasticity coincide with those predicted by the flow theory. Moreover, this result holds for both strain rate-dependent and strain rate-independent materials.

- Comparisons between the predictions of the developed model (with solid lines) and reference results reported in [9] (with dotted graphs) reveal perfect agreement, thus validating the developed numerical tools.

\subsection{Metal/elastomer bilayer}

In this subsection, we investigate the ductility limits of substrate-supported metal layers. For comparison purposes, two combinations of constitutive models will be considered; namely, a metal layer modeled by the flow theory of plasticity supported by a neo-Hookean elastomer substrate and a metal layer modeled by the deformation theory of plasticity supported by a neo-Hookean elastomer substrate. In what follows, shorthand notations will be adopted for the above-described metal/elastomer bilayers, which will be designated as FT/NH and DT/ $\mathrm{NH}$, respectively. Note that in both cases, the elastomer substrate is modeled by a neo-Hookean law. Unless explicitly stated otherwise, the hardening exponent $n$ of the metal layer and the shear modulus $\mu$ of the elastomer layer are taken equal to 0.22 and $22 \mathrm{MPa}$, respectively. This choice for the elastomer material parameters is based on data for polyurea [30].

In order to emphasize the respective effects of strain rate sensitivity and elastomer relative thickness on localized necking, the evolution of the ratio $\varepsilon_{11}^{\mathrm{B}} / \varepsilon_{11}^{\mathrm{S}}$ as a function of
Fig. 9 Effect of the thickness ratio $\mathrm{H}_{\mathrm{I}} / \mathrm{h}_{\mathrm{I}}$ on the retardation of necking for a metal/elastomer bilayer and different values for the strain rate sensitivity parameter $\left(\xi_{\mathrm{I}}=10^{-2}, \theta_{\mathrm{I}}=0^{\circ}\right): \mathbf{a}$ FT/NH, $\rho=$ $0 ; \mathbf{b}$ DT/NH, $\rho=0 ; \mathbf{c}$ FT/NH, $\rho=$ $1 ; \mathbf{d} \mathrm{DT} / \mathrm{NH}, \rho=1$

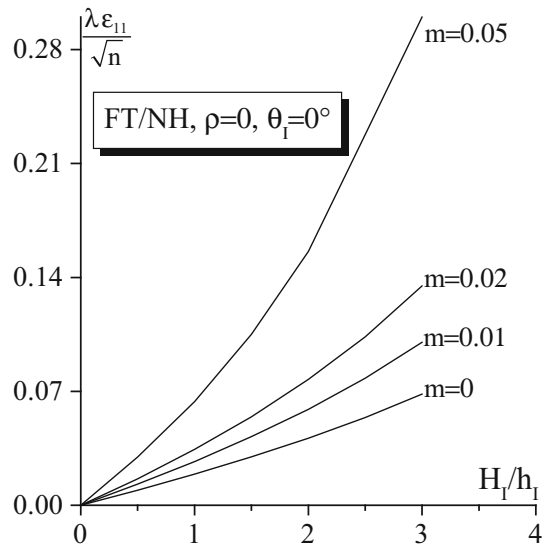

(a)

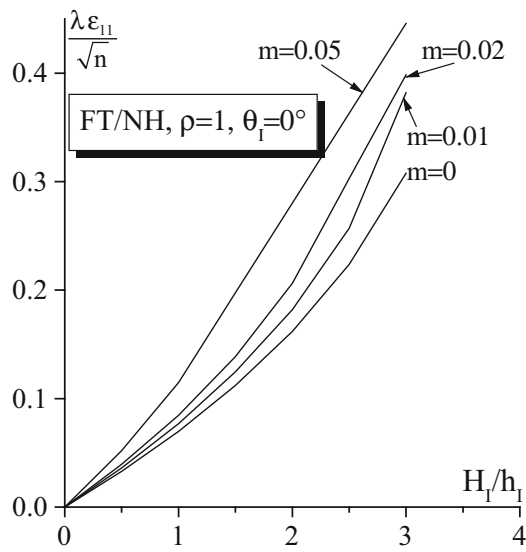

(c)

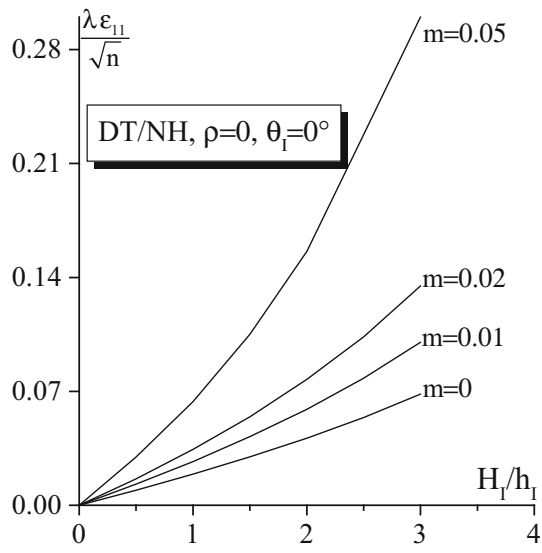

(b)

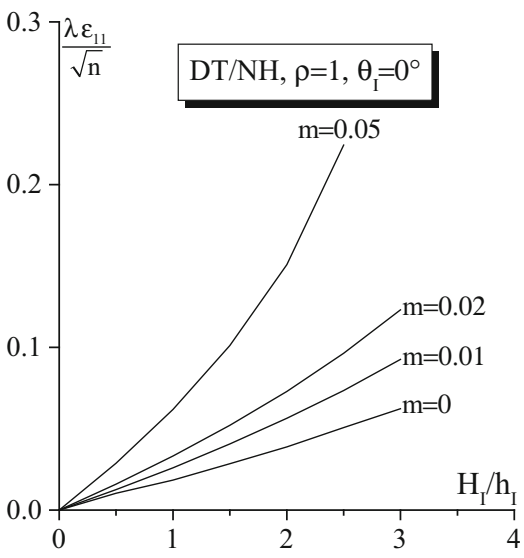

(d) 
the major strain $\varepsilon_{11}^{\mathrm{S}}$ is plotted in Fig. 8. In this figure, three representative strain paths are considered: $\rho=-1 / 2$ (with $\left.\theta_{\mathrm{I}}=15^{\circ}\right), \rho=0$ (with $\theta_{\mathrm{I}}=0^{\circ}$ ), and $\rho=1$ (with $\theta_{\mathrm{I}}=0^{\circ}$ ). The initial imperfection ratio $\xi_{\mathrm{I}}$ is set to $10^{-2}$. The ends of the curves in Fig. 8 correspond to the points where criterion (26) is satisfied. It is observed from this figure that bonding an elastomer substrate to a metal layer significantly increases the value of the critical strain $\varepsilon_{11}^{*}$ of the resulting metal/ elastomer bilayer. More interestingly, the positive role of the elastomer layer in improving the ductility of the bilayer is enhanced when the mechanical behavior of the metal layer is strain rate sensitive. Another observation is that the modeling based on flow theory of plasticity is more sensitive to the addition of an elastomer layer than the DT/NH bilayer combination. This is especially remarkable in the particular case of uniaxial tension $(\rho=-1 / 2)$, where the presence of the elastomer substrate may even guarantee the immunity of the FT/NH bilayer against localized necking when the behavior of the latter is strain rate sensitive (Fig. 8a). Similar to the case of a freestanding metal layer, for the plane-strain tension loading path $(\rho=0)$, the evolution of $\varepsilon_{11}^{\mathrm{B}} / \varepsilon_{11}^{\mathrm{S}}$ as a function of $\varepsilon_{11}^{\mathrm{S}}$ is exactly the same, whatever the constitutive modeling combination considered for the bilayer (FT/NH or DT/NH). For this particular strain path, a relation, similar to Eq. (30), can be derived to describe the evolution of $\varepsilon_{11}^{\mathrm{B}} / \varepsilon_{11}^{\mathrm{S}}$ as a function of $\varepsilon_{11}^{\mathrm{S}}$.

$$
\begin{aligned}
& \mathrm{e}^{-\varepsilon_{11}^{\mathrm{B}}} \quad \mathrm{h}_{\mathrm{I}}^{\mathrm{B}}\left(\frac{2}{\sqrt{3}}\right)^{\mathrm{n}+\mathrm{m}+1} \mathrm{~K}\left(\varepsilon_{11}^{\mathrm{B}}\right)^{\mathrm{n}}\left(\Delta \varepsilon_{11}^{\mathrm{B}}\right)^{\mathrm{m}}+\mu \mathrm{H}_{\mathrm{I}}^{\mathrm{B}}\left(\mathrm{e}^{\left.\left.2 \varepsilon_{11}^{\mathrm{B}}-\mathrm{e}^{-2 \varepsilon_{11}^{\mathrm{B}}}\right)\right)}\right. \\
& \left.=\mathrm{e}^{-\varepsilon_{11}^{\mathrm{S}}} \mathrm{h}_{\mathrm{I}}^{\mathrm{S}}\left(\frac{2}{\sqrt{3}}\right)^{\mathrm{n}+\mathrm{m}+1} \mathrm{~K}\left(\varepsilon_{11}^{\mathrm{S}}\right)^{\mathrm{n}}\left(\Delta \varepsilon_{11}^{\mathrm{S}}\right)^{\mathrm{m}}+\mu \mathrm{H}_{\mathrm{I}}^{\mathrm{S}}\left(\mathrm{e}^{2 \varepsilon_{11}^{\mathrm{S}}-\mathrm{e}^{-2 \varepsilon_{11}^{\mathrm{S}}}}\right)\right) .
\end{aligned}
$$

The respective effect of strain rate sensitivity and elastomer relative thickness on the necking retardation is further investigated in Fig. 9. To quantify this necking delay, the evolution of the retardation factor $\lambda \varepsilon_{11}=\varepsilon_{11}^{\mathrm{L}}-\left.\varepsilon_{11}^{\mathrm{L}}\right|_{\mathrm{H}_{\mathrm{I}}=0}$, normalized by $\sqrt{n}$, as a function of the initial thickness ratio $\mathrm{H}_{\mathrm{I}} / \mathrm{h}_{\mathrm{I}}$ is plotted in Fig. 9. In this figure, the shear modulus of the elastomer substrate is kept equal to $22 \mathrm{MPa}$ for all simulations, while the initial thickness ratio $\mathrm{H}_{\mathrm{I}} / \mathrm{h}_{\mathrm{I}}$ is varied between 0 and 3 . The obtained results reveal that the necking retardation is nearly proportional to the thickness of the elastomer layer. Therefore,
Fig. 10 Evolution of the critical strain $\varepsilon_{11}^{*}$ as a function of the band orientation $\theta$ for a metal/ elastomer bilayer and different values of elastomer relative thickness; comparison of flow theory with deformation theory $(\rho=-0.5, \mathrm{n}=0.22, \mathrm{~m}=0.02): \mathbf{a}$ $\mathrm{FT} / \mathrm{NH}, \xi_{\mathrm{I}}=10^{-2} ; \mathbf{b} \mathrm{DT} / \mathrm{NH}, \xi_{\mathrm{I}}=$ $10^{-2}$; c FT/NH, $\xi_{\mathrm{I}}=2 \times 10^{-2}$; d $\mathrm{DT} / \mathrm{NH}, \xi_{\mathrm{I}}=2 \times 10^{-2}$

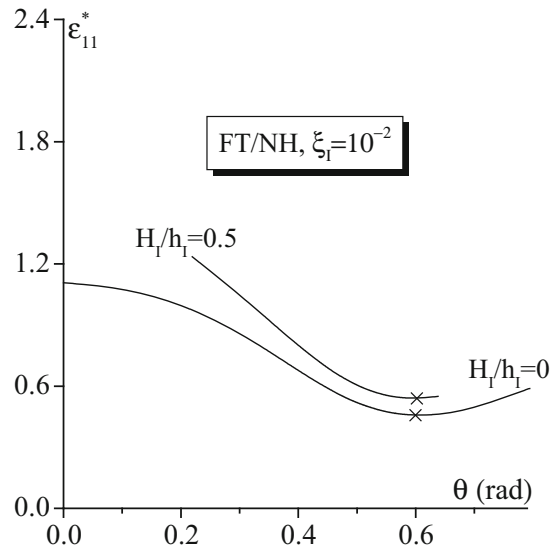

(a)

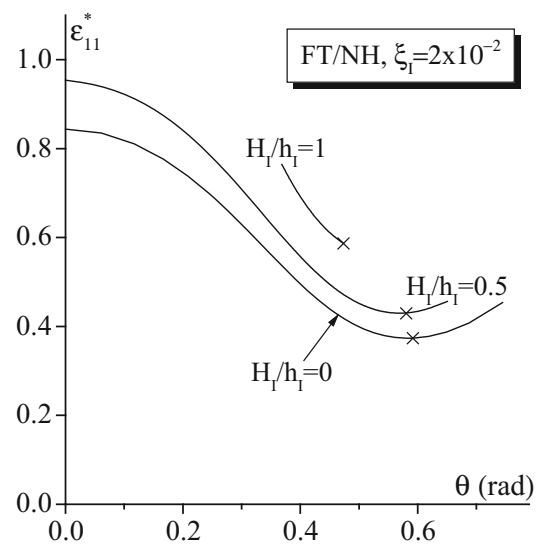

(c)

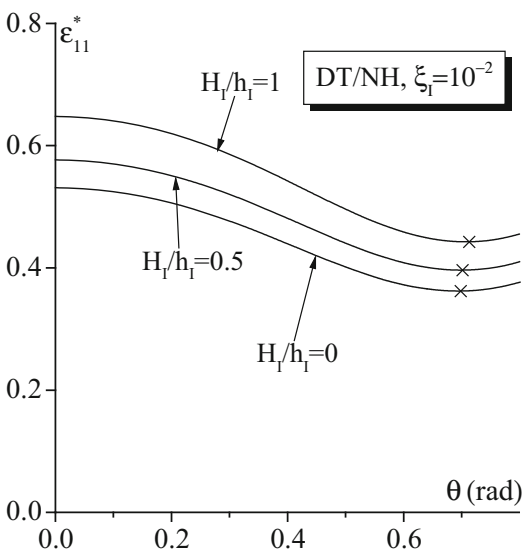

(b)

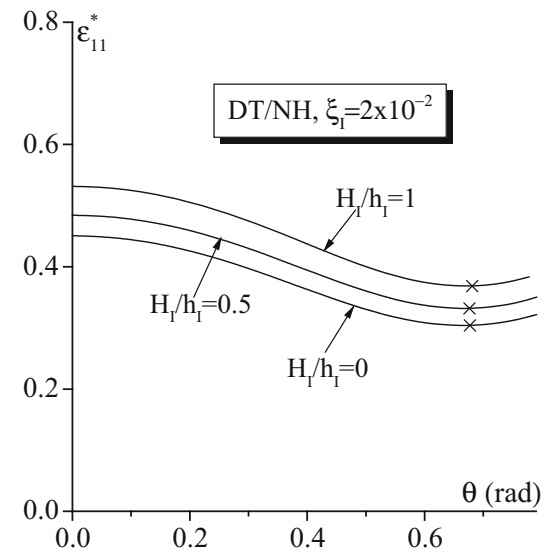

(d) 
it is possible to prevent localized necking in metal/elastomer bilayers by increasing the elastomer relative thickness. This result is due to the fact that elastomer materials exhibit high immunity against localized necking. From a technological point of view, this conclusion is very important for the design of parts and components made of substrate-supported metal layers. Indeed, when allowed by the design constraints of these parts, bonding thin metal layers by (relatively) thick elastomer substrates allows substantially enhancing the ductility of the resulting bilayers, which is desirable in applications involving high stretchability levels. Similar analysis has been carried out to investigate the effect of the elastomer substrate stiffness on the necking retardation in the bilayer. We demonstrated, through this analysis, that bonding a thin but sufficiently stiff elastomer substrate to a metal layer allows retarding or even avoiding, in some special configurations, localized necking in the bilayer. For the sake of brevity, the numerical results corresponding to this analysis are not presented in this paper.

Figure 10 shows the evolution of the critical strain $\varepsilon_{11}^{*}$ as a function of the band orientation $\theta$ of the bilayer, in the case of the uniaxial tensile state. Whenever possible, three values for the initial thickness ratio $\mathrm{H}_{\mathrm{I}} / \mathrm{h}_{\mathrm{I}}$ are used in the different simulations; namely, $0,0.5$, and 1 . Similar to the case of a freestanding metal layer, the critical strains predicted using the FT/NH constitutive modeling for the bilayer are more sensitive to the variation of the band orientation than their counterparts corresponding to the DT/NH combination. Also, it is observed that the necking band orientation (i.e., the band orientation that minimizes the critical strain $\varepsilon_{11}^{*}$ ) is almost independent of the initial thickness ratio $\mathrm{H}_{\mathrm{I}} / \mathrm{h}_{\mathrm{I}}$. Moreover, this trend seems to hold regardless of the bilayer constitutive combination (FT/NH or DT/NH) and of the initial imperfection ratio $\xi_{\mathrm{I}}\left(10^{-2}\right.$ or $\left.2 \times 10^{-2}\right)$.

The respective effect of the strain rate sensitivity parameter $m$ and the initial thickness ratio $\mathrm{H}_{\mathrm{I}} / \mathrm{h}_{\mathrm{I}}$ on the shape and the location of the forming limit diagrams is depicted in Fig. 11. It is observed that for both constitutive combinations of bilayers (FT/NH and DT/NH), the effect of adding an elastomer substrate is essentially to shift the FLD monotonically upwards, thus enhancing the ductility of the bilayer. This result demonstrates the important practical interest of using elastomer substrates in order to retard the necking limit of functional components and parts. As already observed in Fig. 8, the effect of the elastomer layer is more significant when the mechanical behavior of the metal is strain rate dependent.
Fig. 11 Effect of the strain rate sensitivity parameter $\mathrm{m}$ and the elastomer relative thickness $\mathrm{H}_{\mathrm{I}} / \mathrm{h}_{\mathrm{I}}$ on the shape and the location of the predicted FLDs for a metal/ elastomer bilayer: a FT/NH, $\xi_{\mathrm{I}}=$ $10^{-2}$; b DT/NH, $\xi_{\mathrm{I}}=10^{-2}$; c FT/ $\mathrm{NH}, \xi_{\mathrm{I}}=2 \times 10^{-2} ; \mathbf{d} \mathrm{DT} / \mathrm{NH}$, $\xi_{\mathrm{I}}=2 \times 10^{-2}$

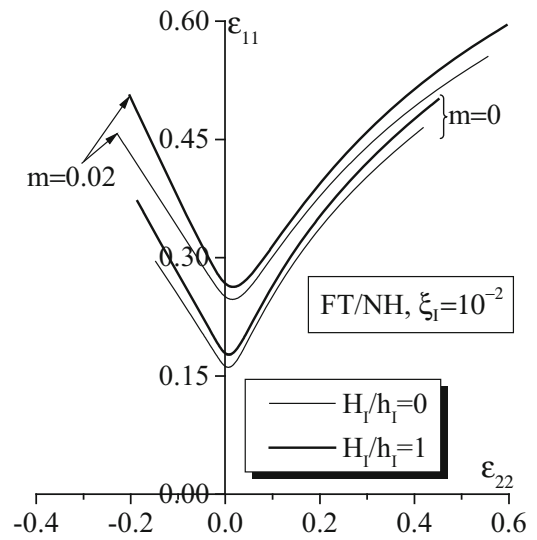

(a)

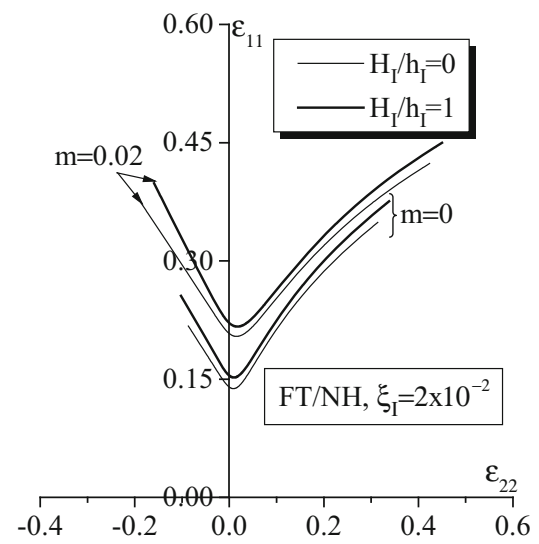

(c)

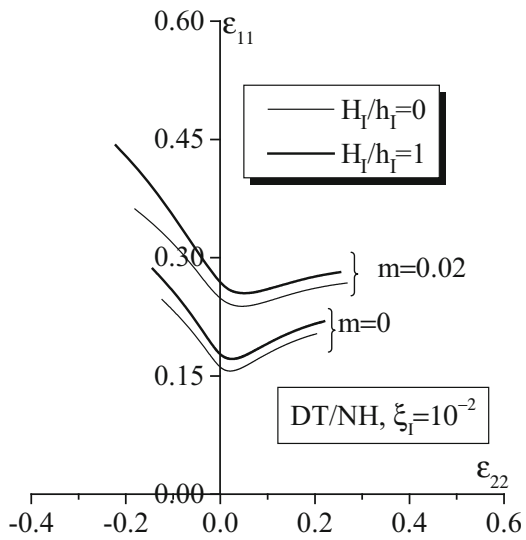

(b)

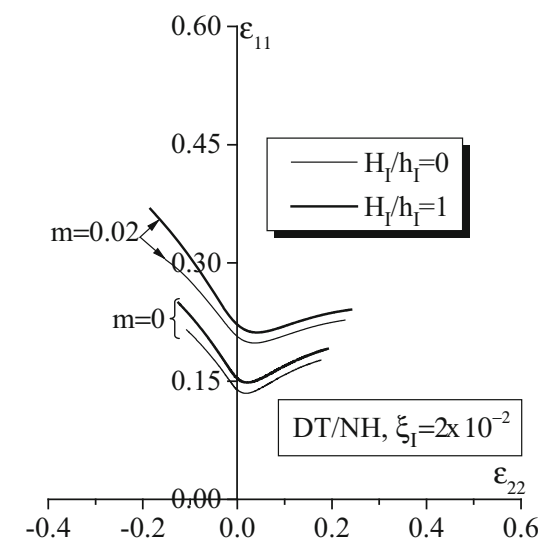

(d) 


\section{Conclusions}

The respective as well as the combined effects of metal strain rate sensitivity and the addition of an elastomer substrate on the occurrence of localized necking in metal/elastomer bilayers has been carefully investigated in this paper. For comparison purposes, the mechanical behavior of the metal has been modeled successively by the large-strain rigid-viscoplastic flow theory and the deformation theory counterpart. However, a neo-Hookean constitutive law has been used to model the elastomer behavior. The metal and the elastomer layers are assumed to be sufficiently thin with an isotropic and incompressible mechanical response. The onset of localized necking is predicted by using the initial imperfection approach. The different predictions correlate well with experimental observations. From the simulation results, key findings may be summarized as follows:

- Strain rate sensitivity substantially retards the occurrence of strain localization in both freestanding metal layers and substrate-supported metal layers.

- The beneficial role of the addition of an elastomer substrate in the enhancement of the ductility of substratesupported metal layers is more important when the mechanical behavior of the metal layer is strain rate dependent than when it is strain rate independent.

- In the range of positive strain paths, the predicted limit strains are noticeably high when the mechanical behavior of the metal layer is described by the flow theory of plasticity.

The theoretical and numerical tools developed in the current contribution can be used, in an industrial context, to provide guidelines and assistance in the design of new generations of electronic devices.

\section{Appendix}

\section{Implicit incremental integration of the equations governing the initial imperfection approach}

The aim of this section is to integrate the equations governing the initial imperfection approach over a typical time step $\left[t_{n}, t_{n+1}\right]$. The material parameters are assumed to have been determined for both layers. Also, the following quantities are assumed to be known at $t_{n}$ :

- $\quad \mathbf{F}^{\mathrm{B}}$ (resp. $\mathbf{F}^{\mathrm{S}}$ ): the deformation gradient in the band (resp. in the safe zone).
- $\varepsilon_{\text {eq }}^{\mathrm{B}}\left(\right.$ resp. $\left.\varepsilon_{\text {eq }}^{\mathrm{S}}\right)$ : the equivalent strain in the band (resp. in the safe zone).

- $\mathrm{h}^{\mathrm{B}}\left(\mathrm{resp} . \mathrm{h}^{\mathrm{S}}\right)$ : the thickness of the metal layer in the band (resp. in the safe zone).

- $\mathrm{H}^{\mathrm{B}}\left(\right.$ resp. $\left.\mathrm{H}^{\mathrm{S}}\right)$ : the thickness of the elastomer layer in the band (resp. in the safe zone).

Due to assumption A2 in Section 2.1.1, the values of $\mathbf{G}^{\mathrm{B}}$, $\mathbf{G}^{\mathrm{S}}, \mathbf{F}^{\mathrm{B}}, \mathbf{F}^{\mathrm{S}}, \varepsilon_{\text {eq }}^{\mathrm{B}}$, and $\varepsilon_{\text {eq }}^{\mathrm{S}}$ in the metal layer are equal to their counterparts in the elastomer layer.

The component $\mathrm{G}_{11}^{\mathrm{S}}$ of the velocity gradient in the safe zone is fixed to 1 over $\left[t_{n}, t_{n+1}\right]$ and, more generally, during the whole deformation. By using Eq. (18), the other components of $\mathbf{G}^{\mathrm{S}}$ can easily be deduced as follows:

$\mathbf{G}^{S}=\left[\begin{array}{ccc}1 & 0 & 0 \\ 0 & \rho & 0 \\ 0 & 0 & -(1+\rho)\end{array}\right]$.

In order to simplify notations, subscript $t_{n+1}$, indicating that the corresponding variable is expressed at time $t_{n+1}$, will be omitted hereinafter, unless otherwise indicated.

Knowing the values of $\mathbf{G}^{\mathrm{S}}$ and the other variables at time $t_{n}$, it is possible to determine the Cauchy stress tensor $\boldsymbol{\sigma}$ in both layers of the safe zone (at time $t_{n+1}$ ):

- Flow theory of plasticity (metal layer): due to the symmetric form of $\mathbf{G}^{\mathrm{S}}$ in Eq. (32), the strain rate $\varepsilon^{\mathrm{s}}$ takes the same expression. The equivalent strain rate $\varepsilon_{\mathrm{eq}}^{\mathrm{s}}$ is computed from $\varepsilon^{\mathrm{s}}$ by using Eq. (2). This allows the equivalent strain at $t_{n=1}$. to be determined by the following relation:

$\varepsilon_{\text {eq }}^{S}=\varepsilon_{\text {eq }}^{S}+\Delta t \dot{\varepsilon}_{\text {eq }}^{S}$.

The equivalent stress $\sigma_{\mathrm{eq}}^{\mathrm{S}}(\mathrm{M})$ is then determined from $\varepsilon_{\mathrm{eq}}^{\mathrm{S}}$ and $\varepsilon_{\mathrm{eq}}^{\mathrm{S}}$ by using Eq. (4), which allows the deviatoric stress tensor $\mathbf{S}^{\mathrm{S}}(\mathrm{M})$ to be computed via Eq. (3). The Cauchy stress tensor $\boldsymbol{\sigma}^{\mathrm{S}}(\mathrm{M})$ is finally derived from the deviatoric stress tensor $\mathbf{S}^{\mathrm{S}}(\mathrm{M})$ by using Eqs. (9) and (12)

- Deformation theory of plasticity (metal layer): in this case, the deformation gradient is first computed (at time $t_{n+1}$ ) using the following relation:

$\mathbf{F}^{\mathrm{S}}=\mathrm{e}^{\Delta \mathrm{t} \mathbf{G}^{\mathrm{S}}} \mathbf{F}_{\mathrm{t}_{\mathrm{n}}}^{\mathrm{S}}$.

Then, the left Cauchy-Green stretch tensor $\mathbf{V}^{\mathrm{S}}$, which is equal to $\sqrt{\mathbf{F}^{\mathrm{S}} \mathbf{F}^{\mathrm{ST}}}$, and the associated logarithmic tensor $\ln$ 
$\mathbf{V}$ are calculated. This allows the equivalent strain $\varepsilon_{\mathrm{eq}}^{\mathrm{S}}$ to be determined as follows:

$\varepsilon_{\mathrm{eq}}^{\mathrm{S}}=\sqrt{(2 / 3) \ln \mathbf{V}: \ln \mathbf{V}}$.

Thus, the equivalent strain rate $\dot{\varepsilon}_{\text {eq }}^{\mathrm{S}}$ is derived from $\varepsilon_{\text {eq }}^{\mathrm{S}}$ and $\varepsilon_{\text {eq }}^{S} t_{n}$ by using the following relation:

$\dot{\varepsilon}_{\mathrm{eq}}^{\mathrm{S}}=\frac{\varepsilon_{\mathrm{eq}}^{\mathrm{S}}-\varepsilon_{\mathrm{eq}}^{\mathrm{S}} \mathrm{t}_{\mathrm{n}}}{\Delta \mathrm{t}}$.

The secant modulus $\mathrm{E}_{\mathrm{S}}$ is then computed by inserting expressions (35) and (36) for $\varepsilon_{\mathrm{eq}}^{\mathrm{S}}$ and $\dot{\varepsilon}_{\mathrm{eq}}^{\mathrm{S}}$ into Eq. (8). Finally, Eq. (6) is used to determine $\mathbf{S}^{\mathrm{S}}(\mathbf{M})$ and, similarly to the flow theory case, the Cauchy stress tensor $\boldsymbol{\sigma}^{\mathrm{S}}(\mathrm{M})$ is derived from the deviatoric stress tensor $\mathbf{S}^{\mathrm{S}}(\mathrm{M})$ by using Eqs. (9) and $(12)_{(1)}$.

- Neo-Hookean model (elastomer layer): the left CauchyGreen stretch tensor $\mathbf{V}^{\mathrm{S}}$ is computed from the expression of $\mathbf{F}^{\mathrm{S}}$. Then, the Cauchy stress tensor $\boldsymbol{\sigma}^{\mathrm{S}}(\mathrm{E})$ is determined from tensor $\mathbf{V}^{\mathrm{S}}$ by using Eqs. (10) and (12) (2).

Also, the current orientation of the band $\theta$ (at time $t_{n+1}$ ) should be computed by using Eq. (24)

$\operatorname{Tan}(\theta)=\mathrm{e}^{(1-\rho) \int_{0}^{\mathrm{t}_{\mathrm{n}}+1} \mathrm{G}_{11}^{\mathrm{S}} \mathrm{dt}} \operatorname{Tan}\left(\theta_{\mathrm{I}}\right)$.
Because the value of $\mathrm{G}_{11}^{\mathrm{S}}$ is held constant and is fixed to 1 during the deformation, Eq. (37) can be rewritten equivalently as

$\operatorname{Tan}(\theta)=\mathrm{e}^{(1-\rho) \mathrm{t}_{\mathrm{n}+1}} \operatorname{Tan}\left(\theta_{\mathrm{I}}\right)$.

Hence, the current orientation of the band, which is function of the strain-path ratio $\rho$, is known at the end of the time increment. Therefore, the normal $\overrightarrow{\boldsymbol{n}}$ to the band, which is equal to $(\cos (\theta), \sin (\theta), 0)$, is also known at $t_{n+1}$.

The velocity gradient in the band is obtained from Eqs. (20) and (32), which reads

$\mathbf{G}^{\mathrm{B}}=\left[\begin{array}{ccc}1+\dot{\mathrm{c}}_{1} n_{1} & \dot{\mathrm{c}}_{1} n_{2} & 0 \\ \dot{\mathrm{c}}_{2} n_{1} & \rho+\dot{\mathrm{c}}_{2} n_{2} & 0 \\ 0 & 0 & -(1+\rho)-\dot{\mathrm{c}}_{1} n_{1}-\dot{\mathrm{c}}_{2} n_{2}\end{array}\right]$.

Accordingly, $\mathbf{G}^{\mathrm{B}}$ only depends on two scalar unknowns: $\dot{c}_{1}$ and $\dot{c}_{2}$. Following the same procedures as those used for the determination of the Cauchy stress tensors in the safe zone, the Cauchy stress tensor $\sigma^{\mathrm{B}}$ in the different layers of the band can be easily expressed as function of $\dot{c}_{1}$ and $\dot{c}_{2}$.

On the other hand, the current thicknesses of the metal and elastomer layers, both in the safe zone and in the band, can be written in the following incremental forms:

$\mathrm{h}^{\mathrm{S}}=\mathrm{h}_{\mathrm{t}_{\mathrm{n}}}^{\mathrm{S}} \mathrm{e}^{\Delta \mathrm{t} \mathrm{G}_{33}^{\mathrm{S}}} ; \quad \mathrm{h}^{\mathrm{B}}=\mathrm{h}_{\mathrm{t}_{\mathrm{n}}^{\mathrm{B}}}^{\mathrm{B}} \mathrm{et}^{\Delta \mathrm{t} \mathrm{G}_{33}^{\mathrm{B}}} ; \quad \mathrm{H}^{\mathrm{S}}=\mathrm{H}_{\mathrm{t}_{\mathrm{n}}}^{\mathrm{S}} \mathrm{e}^{\Delta \mathrm{t} \mathrm{G}_{33}^{\mathrm{S}}} ; \quad \mathrm{H}^{\mathrm{B}}=\mathrm{H}_{\mathrm{t}_{\mathrm{n}}}^{\mathrm{B}} \mathrm{e}^{\Delta \mathrm{t}_{33}^{\mathrm{B}}}$.

Considering the expressions of $\mathrm{G}_{33}^{\mathrm{S}}$ and $\mathrm{G}_{33}^{\mathrm{B}}$ given by Eqs. (32) and (39), the expressions of $\mathrm{h}^{\mathrm{S}}, \mathrm{h}^{\mathrm{B}}, \mathrm{H}^{\mathrm{S}}$, and $\mathrm{H}^{\mathrm{B}}$ in Eq. (40) can be expressed more explicitly as

$\mathrm{h}^{\mathrm{S}}=\mathrm{h}_{\mathrm{t}_{\mathrm{n}}}^{\mathrm{S}} \mathrm{e}^{-\Delta \mathrm{t}(1+\rho)} \quad ; \quad \mathrm{h}^{\mathrm{B}}=\mathrm{h}_{\mathrm{t}_{\mathrm{n}}}^{\mathrm{B}} \mathrm{e}^{-\Delta \mathrm{t}\left(1+\rho+\dot{\mathrm{c}}_{1} \eta_{1}+\dot{\mathrm{c}}_{2} n_{2}\right)} \quad ; \quad \mathrm{H}^{\mathrm{S}}=\mathrm{H}_{\mathrm{t}_{\mathrm{n}}}^{\mathrm{S}} \mathrm{e}^{-\Delta \mathrm{t}(1+\rho)} \quad ; \quad \mathrm{H}^{\mathrm{B}}=\mathrm{H}_{\mathrm{t}_{\mathrm{n}}}^{\mathrm{B}} \mathrm{e}^{-\Delta \mathrm{t}\left(1+\rho+\dot{\mathrm{c}}_{1} \eta_{1}+\dot{\mathrm{c}}_{2} n_{2}\right)}$,

thus revealing that $\mathrm{h}^{\mathrm{S}}$ and $\mathrm{H}^{\mathrm{S}}$ are readily computed in terms of the known quantities $\mathrm{h}_{\mathrm{t}_{\mathrm{n}}}^{\mathrm{S}}, \mathrm{H}_{\mathrm{t}_{\mathrm{n}}}^{\mathrm{S}}, \Delta \mathrm{t}$, and $\rho$. However, thicknesses $\mathrm{h}^{\mathrm{B}}$ and $\mathrm{H}^{\mathrm{B}}$ are still unknown, as they depend on $\mathrm{c}_{1}$ and $\mathrm{c}_{2}$.

The equilibrium Eq. (25) can be expressed in the following indexform: 
$\forall \mathrm{i}=1,2,3: \quad\left(\mathrm{h}^{\mathrm{B}} \sigma_{\mathrm{ij}}^{\mathrm{B}}(\mathrm{M})+\mathrm{H}^{\mathrm{B}} \sigma_{\mathrm{ij}}^{\mathrm{B}}(\mathrm{E})\right) \cdot \boldsymbol{n}_{\mathrm{j}}=\left(\mathrm{h}^{\mathrm{S}} \sigma_{\mathrm{ij}}^{\mathrm{S}}(\mathrm{M})+\mathrm{H}^{\mathrm{S}} \sigma_{\mathrm{ij}}^{\mathrm{S}}(\mathrm{E})\right) \cdot \boldsymbol{n}_{\mathrm{j}} \quad ; \quad \mathrm{j}=1,2,3$.

As the unit vector $\overrightarrow{\boldsymbol{n}}$ normal to the band lies in the plane of the sheet, as illustrated in Fig. 1, its third component $\boldsymbol{n}_{3}$ is equal to 0 .
Furthermore, by virtue of the plane-stress conditions, $\sigma_{\mathrm{i} 3}^{\mathrm{B}}$ and $\sigma_{\mathrm{i} 3}^{\mathrm{S}}$ are equal to 0 . Therefore, Eq. (42) is reduced to a $2 \mathrm{D}$ relation

$\forall \mathrm{i}=1,2: \quad\left(\mathrm{h}^{\mathrm{B}} \sigma_{\mathrm{ij}}^{\mathrm{B}}(\mathrm{M})+\mathrm{H}^{\mathrm{B}} \sigma_{\mathrm{ij}}^{\mathrm{B}}(\mathrm{E})\right) \cdot \boldsymbol{n}_{\mathrm{j}}=\left(\mathrm{h}^{\mathrm{S}} \sigma_{\mathrm{ij}}^{\mathrm{S}}(\mathrm{M})+\mathrm{H}^{\mathrm{S}} \sigma_{\mathrm{ij}}^{\mathrm{S}}(\mathrm{E})\right) \cdot \boldsymbol{n}_{\mathrm{j}} \quad ; \quad \mathrm{j}=1,2$.

This formulation for the equilibrium equation restricted to the sheet plane may be regarded as a system of two scalar equations with two unknowns $\dot{\mathrm{c}}_{1}$ and $\dot{\mathrm{c}}_{2}$
$\mathbf{R}\left(\dot{\mathrm{c}}_{1}, \dot{\mathrm{c}}_{2}\right)=\mathbf{0}$

where the components of the residual vector $\mathbf{R}$ are defined by

$$
\left\{\begin{array}{l}
\mathrm{R}_{1}\left(\dot{\mathrm{c}}_{1}, \dot{\mathrm{c}}_{2}\right)=\left(\mathrm{h}^{\mathrm{B}} \sigma_{1 \mathrm{j}}^{\mathrm{B}}(\mathrm{M})+\mathrm{H}^{\mathrm{B}} \sigma_{1 \mathrm{j}}^{\mathrm{B}}(\mathrm{E})\right) \boldsymbol{n}_{\mathrm{j}}-\left(\mathrm{h}^{\mathrm{S}} \sigma_{1 \mathrm{~s}}^{\mathrm{S}}(\mathrm{M})+\mathrm{H}^{\mathrm{S}} \sigma_{1 \mathrm{j}}^{\mathrm{S}}(\mathrm{E})\right) \boldsymbol{n}_{\mathrm{j}}=0 \\
\mathrm{R}_{2}\left(\dot{\mathrm{c}}_{1}, \dot{\mathrm{c}}_{2}\right)=\left(\mathrm{h}^{\mathrm{B}} \sigma_{2 \mathrm{j}}^{\mathrm{B}}(\mathrm{M})+\mathrm{H}^{\mathrm{B}} \sigma_{2 \mathrm{j}}^{\mathrm{B}}(\mathrm{E})\right) \boldsymbol{n}_{\mathrm{j}}-\left(\mathrm{h}^{\mathrm{S}} \sigma_{2 \mathrm{j}}^{\mathrm{S}}(\mathrm{M})+\mathrm{H}^{\mathrm{S}} \sigma_{2 \mathrm{j}}^{\mathrm{S}}(\mathrm{E})\right) \boldsymbol{n}_{\mathrm{j}}=0
\end{array} \quad ; \mathrm{j}=1,2 .\right.
$$

Equation (45) represents a set of nonlinear equations, which are iteratively solved by the Newton-Raphson method. The function fsolve in Matlab is used to find the roots of Eq. (45) and then to compute the unknowns $\dot{c}_{1}$ and $\dot{c}_{2}$. Ultimately, the determination of $\dot{c}_{1}$ and $\dot{c}_{2}$ allows the computation of the different mechanical and geometric quantities at $t_{n+1}$.

\section{References}

1. Keeler SP, Backofen WA (1963) Plastic instability and fracture in sheets stretched over rigid punches. ASM Trans Q 56:25-48

2. Goodwin GM (1968) Application of strain analysis to sheet metal forming problems in the press shop. SAE Technical Paper 680093. SAE International

3. Hill R (1952) On discontinuous plastic states, with special reference to localized necking in thin sheets. J Mech Phys Solids 1:19-30

4. Stören S, Rice JR (1975) Localized necking in thin sheets. J Mech Phys Solids 23:421-441

5. Hutchinson JW, Neale KW (1978) Sheet necking-II. Timeindependent behavior. In: Koistinen DP, Wang NM (eds). Plenum, New York, pp 127-153

6. Ben Bettaieb M, Abed-Meraim F (2015) Investigation of localized necking in substrate-supported metal layers: comparison of bifurcation and imperfection analyses. Int J Plast 65:168-190

7. Ghosh AK (1977) The influence of strain hardening and strain-rate sensitivity on sheet metal forming. J Eng Mater Technol 99:264 274

8. Hutchinson JW, Neale KW (1977) Influence of strain-rate sensitivity on necking under uniaxial tension. Acta Metall 25:839-846

9. Hutchinson JW, Neale KW (1978) Sheet necking-III. Strain rate effects. In: Koistinen DP, Wang NM (eds). Plenum, New York, pp 269-258

10. Marciniak Z, Kuczynski K (1967) Limit strains in the processes of stretch-forming sheet metal. Int J Mech Sci 9:609-620
11. Neale KW, Chater E (1980) Limit strain predictions for strain-rate sensitive anisotropic sheets. Int J Mech Sci 22:563-574

12. Li MY, Zhu X, Chu E (2012) Effect of strain rate sensitivity on FLDs - an instability approach. Int J Mech Sci 64:273-279

13. Chiu SL, Leu J, Ho PS (1994) Fracture of metal-polymer line structures. I. Semiflexible polyimide. J App Phys 76: $5136-5142$

14. Hommel M, Kraft O (2001) Deformation behavior of thin copper films on deformable substrates. Acta Mater 49:3935-3947

15. Alaca BE, Saif MTA, Sehitoglu H (2002) On the interface debond at the edge of a thin film on a thick substrate. Acta Mater 50:11971209

16. Xue ZY, Hutchinson JW (2007) Neck retardation and enhanced energy absorption in metal/elastomer bilayers. Mech Mater 39: 473-487

17. Xue ZY, Hutchinson JW (2008) Neck development in metal/ elastomer bilayers under dynamic stretchings. Int J Solids Struct 45:3769-3778

18. Cordill MJ, Taylor A, Schalko J, Dehm G (2010) Fracture and delamination of chromium thin films on polymer substrates. Metall Mater Trans A 41A:870-875

19. Cotton DPJ, Graz IM, Lacour SP (2009) A multifunctional capacitive sensor for stretchable electronic skins. IEEE Sensors J 9:20082009

20. Lacour SP, Jones J, Wagner S, Li T, Suo Z (2005) Stretchable interconnects for elastic electronic surfaces. Proc IEEE 93:14591467

21. Hsu PH, Bhattacharya R, Gleskova H, Xi Z, Suo Z, Wagner S, Sturm JC (2002) Thin-film transistor circuits on large-area spherical surfaces. Appl Phys Lett 81:1723-1725

22. Gleskova H, Wagner S, Suo Z (1999) Stability of amorphous silicon transistors under extreme in-plane strain. Appl Phys Lett 75:30113013

23. Lumelsky VJ, Shur MS, Wagner S (2001) Sensitive skin. IEEE Sensors J 1:41-51

24. Wagner S, Bonderover E, Jordan WB, Sturm JC (2002) Electrotextiles: concepts and challenges. Int J High Speed Electron Syst 12:391-399 
25. Jia Z, Li T (2013) Necking limit of substrate-supported metal layers under biaxial in-plane loading. Int J Plast 51:65-79

26. Rice JR (1976) The localization of plastic deformation. In: 14th International Congress of Theoretical and Applied Mechanics, pp 207-220

27. Hunter SC (1979) Some exact solutions in the theory of finite elasticity for incompressible neo-Hookean materials. Int J Mech Sci 21: 203-211

28. Rajagopal KR (1998) On a class of elastodynamic motions in a neoHookean elastic solid. Int J Non-Linear Mech 33:397-405
29. Hutchinson JW, Neale KW, Needleman A (1978) Sheet necking-I. Validity of plane stress assumptions of the long wavelength approximation. In: Koistinen DP, Wang NM (eds). Plenum, New York, pp $111-126$

30. Amirkhizi AV, Isaacs J, McGee J, Nemat-Nasser S (2006) An experimentally-based viscoelastic constitutive model for polyurea including pressure and temperature effects. Philos Mag 86:5847-5866 